\title{
Front Matter: Volume 9153
}

, "Front Matter: Volume 9153," Proc. SPIE 9153, Millimeter, Submillimeter, and Far-Infrared Detectors and Instrumentation for Astronomy VII, 915301 (27 August 2014); doi: 10.1117/12.2075309

EDent: SPIE Astronomical Telescopes + Instrumentation, 2014, Montréal, Quebec, Canada 


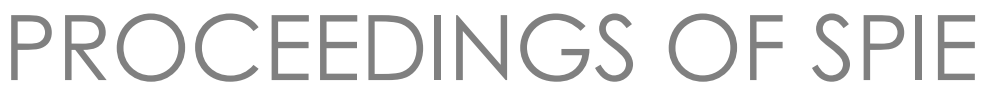

\title{
Millimeter, Submillimeter, and Far-Infrared Detectors and Instrumentation for Astronomy VII
}

\author{
Wayne S. Holland \\ Jonas Zmuidzinas \\ Editors
}

\section{4-27 June 2014 \\ Montréal, Canada}

Sponsored by

SPIE

Cooperating Organizations

American Astronomical Society (United States) • Australian Astronomical Observatory (Australia) • Association of Universities for Research in Astronomy (AURA) • Canadian Astronomical Society (CASCA) (Canada) • Canadian Space Agency (Canada) • European Astronomical Society (Switzerland) • European Southern Observatory (Germany) • National Radio Astronomy Observatory • Royal Astronomical Society (United Kingdom) • Science \& Technology Facilities Council (United Kingdom)

Published by

SPIE 
The papers included in this volume were part of the technical conference cited on the cover and title page. Papers were selected and subject to review by the editors and conference program committee. Some conference presentations may not be available for publication. The papers published in these proceedings reflect the work and thoughts of the authors and are published herein as submitted. The publisher is not responsible for the validity of the information or for any outcomes resulting from reliance thereon.

Please use the following format to cite material from this book:

Author(s), "Title of Paper," in Millimeter, Submillimeter, and Far-Infrared Detectors and Instrumentation for Astronomy VII, edited by Wayne S. Holland, Jonas Zmuidzinas, Proceedings of SPIE Vol. 9153 (SPIE, Bellingham, WA, 2014) Article CID Number.

ISSN: 0277-786X

ISBN: 9780819496218

Published by

SPIE

P.O. Box 10, Bellingham, Washington 98227-0010 USA

Telephone +1 3606763290 (Pacific Time) · Fax +1 3606471445

SPIE.org

Copyright (@ 2014, Society of Photo-Optical Instrumentation Engineers.

Copying of material in this book for internal or personal use, or for the internal or personal use of specific clients, beyond the fair use provisions granted by the U.S. Copyright Law is authorized by SPIE subject to payment of copying fees. The Transactional Reporting Service base fee for this volume is $\$ 18.00$ per article (or portion thereof), which should be paid directly to the Copyright Clearance Center (CCC), 222 Rosewood Drive, Danvers, MA 01923. Payment may also be made electronically through CCC Online at copyright.com. Other copying for republication, resale, advertising or promotion, or any form of systematic or multiple reproduction of any material in this book is prohibited except with permission in writing from the publisher. The CCC fee code is 0277-786X/14/\$18.00.

Printed in the United States of America.

Publication of record for individual papers is online in the SPIE Digital Library.

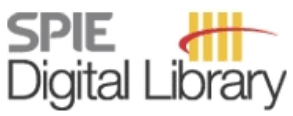

SPIEDigitalLibrary.org

Paper Numbering: Proceedings of SPIE follow an e-First publication model, with papers published first online and then in print and on CD-ROM. Papers are published as they are submitted and meet publication criteria. A unique, consistent, permanent citation identifier (CID) number is assigned to each article at the time of the first publication. Utilization of CIDs allows articles to be fully citable as soon as they are published online, and connects the same identifier to all online, print, and electronic versions of the publication. SPIE uses a six-digit CID article numbering system in which:

- The first four digits correspond to the SPIE volume number.

- The last two digits indicate publication order within the volume using a Base 36 numbering

system employing both numerals and letters. These two-number sets start with 00, 01, 02, 03, 04, $05,06,07,08,09,0 A, 0 B \ldots 0 Z$, followed by 10-1Z, 20-2Z, etc.

The CID Number appears on each page of the manuscript. The complete citation is used on the first page, and an abbreviated version on subsequent pages. Numbers in the index correspond to the last two digits of the six-digit CID Number. 


\title{
Contents
}

\section{Part One}

\author{
xxix Conference Committee
}

\section{SESSION 1 CURRENT/NEAR-TERM CAMERAS AND ARRAYS}

915302 The NIKA 2012-2014 observation campaigns: control of systematic effects and results [9153-1]

A. Catalano, R. Adam, Lab. de Physique Subatomique et de Cosmologie, CNRS, Univ. of Grenoble (France); A. Adane, IRAM - Institut de Radio Astronomie Millimétrique (France); P. Ade, Cardiff Univ. (United Kingdom); P. André, Lab. AIM, CNRS, Univ. Paris Dideroł (France) and IRFU-CEA (France); A. Beelen, Institut d'Astrophysique Spatiale, CNRS, Univ. Paris Sud (France); B. Belier, Institut d'Electronique Fondamentale, Univ. Paris Sud (France); A. Benoît, Institut NÉEL, CNRS (France) and Univ. de Grenoble (France); A. Bideaud, Cardiff Univ. (United Kingdom); N. Billot, IRAM - Instituto de RadioAstronomía Milimétrica (Spain); N. Boudou, Institut NÉEL, CNRS (France) and Univ. de Grenoble (France); O. Bourrion, Lab. de Physique Subatomique et de Cosmologie, CNRS, Univ. of Grenoble (France); M. Calvo, Institut NÉEL, CNRS (France) and Univ. de Grenoble (France); G. Coiffard, IRAM - Institut de Radio Astronomie Millimétrique (France); B. Comis, Lab. de Physique Subatomique et de Cosmologie, CNRS, Univ. of Grenoble (France); A. D'Addabbo, Institut NÉEL, CNRS (France) and Univ. de Grenoble (France) and Univ. degli Studi di Roma La Sapienza (Italy); F.-X. Désert, Institut de Planétologie et d'Astrophysique de Grenoble, CNRS, Univ. de Grenoble (France); S. Doyle, Cardiff Univ. (United Kingdom); J. Goupy, Institut NÉEL, CNRS (France) and Univ. de Grenoble (France); C. Kramer, IRAM - Instituto de RadioAstronomía Milimétrica (Spain); S. Leclercq, IRAM - Institut de RadioAstronomie Millimétrique (France); J. F. Macías-Pérez, Lab. de Physique Subatomique et de Cosmologie, CNRS, Univ. of Grenoble (France); J. Martino, Institut d'Astrophysique Spatiale, CNRS, Univ. Paris Sud (France); P. Mauskopf, SESE, Arizona State Univ. (United States) and Univ. of Cardiff (United Kingdom); F. Mayet, Lab. de Physique Subatomique et de Cosmologie, CNRS, Univ. of Grenoble (France); A. Monfardini, Institut NÉEL, CNRS (France) and Univ. de Grenoble (France); F. Pajot, Institut d'Astrophysique Spatiale, CNRS, Univ. Paris Sud (France);

E. Pascale, Cardiff Univ. (United Kingdom); L. Perotto, Lab. de Physique Subatomique et de Cosmologie, CNRS, Univ. of Grenoble (France); E. Pointecouteau, Institut de Recherche en Astrophysique et Planétologie, CNRS, Univ. de Toulouse (France) and Institut de Recherche en Astrophysique et Planétologie, CNRS (France); N. Ponthieu, Institut de Planétologie et d'Astrophysique de Grenoble, CNRS, Univ. de Grenoble (France); V. Revéret, Lab. AIM, CNRS, Univ. Paris Diderot (France) and IRFU-CEA (France); A. Ritacco, Lab. de Physique Subatomique et de Cosmologie, CNRS, Univ. of Grenoble (France); L. Rodriguez, Lab. AIM, CNRS, Univ. Paris Diderot (France) and IRFU-CEA (France); G. Savini, Univ. College London (United Kingdom); K. Schuster, IRAM - Institut de Radio Astronomie Millimétrique (France); A. Sievers, IRAM - Instituto de RadioAstronomía Milimétrica (Spain); C. Tucker, Cardiff Univ. (United Kingdom); R. Zylka, IRAM - Institut de Radio Astronomie Millimétrique (France) 
915303 SCUBA-2: an update on the performance of the 10,000 pixel bolometer camera after two years of science operation at the JCMT [9153-2]

D. Bintley, Joint Astronomy Ctr. (United States); W. S. Holland, Royal Observatory, UK Astronomy Technology Ctr. (United Kingdom) and Royal Observatory, Univ. of Edinburgh (United Kingdom); M. J. MacIntosh, Royal Observatory, UK Astronomy Technology Ctr. (United Kingdom); P. Friberg, G. S. Bell, D. A. Berke, D. S. Berry, R. M. Berthold, J. L. Cookson, I. M. Coulson, M. J. Currie, J. T. Dempsey, Joint Astronomy Ctr. (United States); A. G. Gibb, The Univ. of British Columbia (Canada); B. H. Gorges, S. F. Graves, Joint Astronomy Ctr. (United States); T. Jenness, Joint Astronomy Ctr. (United States) and Cornell Univ. (United States); D. I. Johnstone, H. A. L. Parsons, H. S. Thomas, C. Walther, J. G. A. Wouterloot, Joint Astronomy Ctr. (United States)

915304 The status of MUSIC: the multiwavelength sub-millimeter inductance camera [9153-3] J. Sayers, California Institute of Technology (United States); C. Bockstiegel, National Institute of Standards and Technology (United States); S. Brugger, Univ. of Colorado at Boulder (United States); N. G. Czakon, Academia Sinica (Taiwan); P. K. Day, Jet Propulsion Lab. (United States); T. P. Downes, Univ. of Wisconsin (United States); R. P. Duan, California Institute of Technology (United States); J. Gao, National Institute of Standards and Technology (United States); A. K. Gill, J. Glenn, Univ. of Colorado at Boulder (United States); S. R. Golwala, M. I. Hollister, A. Lam, California Institute of Technology (United States); H. G. LeDuc, Jet Propulsion Lab. (United States); P. R. Maloney, Univ. of Colorado at Boulder (United States); B. A. Mazin, S. G. McHugh, Univ. of California, Santa Barbara (United States); D. A. Miller, California Institute of Technology (United States);

A. K. Mroczkowski, U.S. Naval Research Lab. (United States); O. Noroozian, NASA Goddard Space Flight Ctr. (United States); H. T. Nguyen, Jet Propulsion Lab. (United States); J. A. Schlaerth, S. R. Siegel, A. Vayonakis, California Institute of Technology (United States); P. R. Wilson, Jet Propulsion Lab. (United States); J. Zmuidzinas, California Institute of Technology (United States) and Jet Propulsion Lab. (United States)

915305 The ArTéMiS wide-field submillimeter camera: preliminary on-sky performance at 350 microns [9153-4]

V. Revéret, P. André, J. Le Pennec, M. Talvard, AIM Lab., CNRS, Paris Saclay (France) and IRFU-CEA (France); P. Agnèse, A. Arnaud, Lab. d'Electronique et Technologie de I'Information, CEA (France); L. Clerc, Service des Basses Températures, CEA (France); C. de Breuck, European Southern Observatory (Germany); J.-C. Cigna, Lab. d'Electronique et Technologie de I'Information, CEA (France); C. Delisle, E. Doumayrou, AIM Lab., CNRS, Paris Saclay (France) and IRFU-CEA (France); L. Duband, Service des Basses Températures, CEA (France); D. Dubreuil, L. Dumaye, AIM Lab., CNRS, Paris Saclay (France) and IRFU-CEA (France); E. Ercolani, Service des Basses Températures, CEA (France); P. Gallais, E. Groult, AIM Lab., CNRS, Paris Saclay (France) and IRFU-CEA (France); T. Jourdan, Service des Basses Températures, CEA (France); B. Leriche, Institut d'Astrophysique Spatiale, CNRS, Univ. Paris Sud (France); B. Maffei, The Univ. of Manchester (United Kingdom); M. Lortholary, J. Martignac, AIM Lab., CNRS, Paris Saclay (France); W. Rabaud, Lab. d'Electronique et Technologie de l'Information, CEA (France); J. Relland, Commissariat à l'Énergie Atomique (France); L. Rodriguez, AIM Lab., CNRS, Paris Saclay (France) and IRFU-CEA (France); A. Vandeneynde, Lab. d'Electronique et Technologie de I'Information, CEA (France); F. Visticot, AIM Lab., CNRS, Paris Saclay (France) and IRFU-CEA (France) 
915308 Large area TES spiderweb bolometer for multi-mode cavity microwave detect [9153-7] M. Biasotti, D. Bagliani, V. Ceriale, D. Corsini, Univ. degli Studi di Genova (Italy) and INFN (Italy); P. De Bernardis, Univ. degli Studi di Roma La Sapienza (Italy); F. Gatti, Univ. degli Studi di Genova (Italy) and INFN (Italy); R. Gualtieri, L. Lamagna, S. Masi, Univ. degli Studi di Roma La Sapienza (Italy); G. Pizzigoni, Univ. degli Studi di Genova (Italy) and INFN (Italy); A. Schillaci, Univ. degli Studi di Roma La Sapienza (Italy)

915309 Monolayer graphene bolometer as a sensitive far-IR detector [9153-8] B. S. Karasik, Jet Propulsion Lab. (United States); C. B. McKitterick, D. E. Prober, Yale Univ. (United States)

$91530 \mathrm{~A}$ Cold-electron bolometers for future $\mathrm{mm}$ and sub-mm sky surveys [9153-9] M. Salatino, P. de Bernardis, Univ. degli Studi di Roma La Sapienza (Italy); S. Mahashabde, L. S. Kuzmin, Chalmers Univ. of Technology (Sweden); S. Masi, Univ. degli Studi di Roma La Sapienza (Italy)

9153 OB Scalable background-limited polarization-sensitive detectors for $\mathrm{mm}$-wave applications [9153-11]

K. Rostem, Johns Hopkins Univ. (United States) and NASA Goddard Space Flight Ctr. (United States); A. Ali, J. W. Appel, C. L. Bennett, Johns Hopkins Univ. (United States); D. T. Chuss, F. A. Colazo, E. Crowe, K. L. Denis, NASA Goddard Space Flight Ctr. (United States); T. Essinger-Hileman, T. A. Marriage, Johns Hopkins Univ. (United States); S. H. Moseley, T. R. Stevenson, D. W. Towner, K. U-Yen, E. J. Wollack, NASA Goddard Space Flight Ctr. (United States)

\section{SESSION $3 \quad$ TRANSITION-EDGE SENSORS: PERFORMANCE AND DEVELOPMENTS}

9153 OE Optical characterization of ultra-sensitive TES bolometers for SAFARI [9153-14] M. D. Audley, G. de Lange, SRON Netherlands Institute for Space Research (Netherlands); J.-R. Gao, SRON Netherlands Institute for Space Research (Netherlands) and Delft Univ. of Technology (Netherlands); P. Khosropanah, SRON Netherlands Institute for Space Research (Netherlands); P. D. Mauskopf, Arizona State Univ. (United States) and Cardiff Univ. (United Kingdom); D. Morozov, Cardiff Univ. (United Kingdom); N. A. Trappe, S. Doherty, National Univ. of Ireland, Maynooth (Ireland); S. Withington, Cavendish Lab., Univ. of Cambridge (United Kingdom)

9153 OF Lithographed spectrometers for tomographic line mapping of the Epoch of Reionization [9153-15]

R. O'Brient, J. J. Bock, California Institute of Technology (United States) and Jet Propulsion Lab. (United States); C. M. Bradford, Jet Propulsion Lab. (United States); A. Crites, California Institute of Technology (United States) and Jet Propulsion Lab. (United States); R. Duan, S. Hailey-Dunsheath, J. Hunacek, California Institute of Technology (United States); R. LeDuc, Jet Propulsion Lab. (United States); E. Shirokoff, The Univ. of Chicago (United States); Z. Staniszewski, California Institute of Technology (United States) and Jet Propulsion Lab. (United States); A. Turner, Jet Propulsion Lab. (United States); M. Zemcov, California Institute of Technology (United States) and Jet Propulsion Lab. (United States) 
$9153 \mathrm{OH}$ The next-generation BLASTPol experiment [9153-17]

B. J. Dober, Univ. of Pennsylvania (United States); P. A. R. Ade, Cardiff Univ. (United Kingdom); P. Ashton, Northwestern Univ. (United States); F. E. Angilè, Univ. of Pennsylvania (United States); J. A. Beall, D. Becker, National Institute of Standards and Technology (United States); K. J. Bradford, G. Che, Arizona State Univ. (United States); H.-M. Cho, National Institute of Standards and Technology (United States); M. J. Devlin, Univ. of Pennsylvania (United States); L. M. Fissel, Northwestern Univ. (United States); Y. Fukui, Nagoya Univ. (Japan); N. Galitzki, Univ. of Pennsylvania (United States); J. Gao, National Institute of Standards and Technology (United States); C. E. Groppi, Arizona State Univ. (United States); S. Hilllbrand, California State Univ., Sacramento (United States); G. C. Hilton, J. Hubmayr, National Institute of Standards and Technology (United States); K. D. Irwin, Stanford Univ. (United States); J. Klein, Univ. of Pennsylvania (United States); J. Van Lanen, D. Li, National Institute of Standards and Technology (United States); Z.-Y. Li, Univ. of Virginia (United States); N. P. Lourie, Univ. of Pennsylvania (United States); H. Mani, Arizona State Univ. (United States); P. G. Martin, Univ. of Toronto (Canada); P. Mauskopf, Arizona State Univ. (United States); F. Nakamura, National Astronomical Observatory of Japan (Japan); G. Novak, Northwestern Univ. (United States); D. P. Pappas, National Institute of Standards and Technology (United States); E. Pascale, Cardiff Univ. (United Kingdom); F. P. Santos, Northwestern Univ. (United States); G. Savini, Univ. College London (United Kingdom); D. Scott, The Univ. of British Columbia (Canada); S. Stanchfield, Univ. of Pennsylvania (United States); J. N. Ullom, National Institute of Standards and Technology (United States); M. Underhill, Arizona State Univ. (United States); M. R. Vissers, National Institute of Standards and Technology (United States); D. Ward-Thompson, Univ. of Central Lancashire (United Kingdom)

9153 0J MUSTANG2: a large focal plan array for the 100 meter Green Bank Telescope [9153-19] S. R. Dicker, Univ. of Pennsylvania (United States); P. A. R. Ade, Cardiff Univ. (United Kingdom); J. Aguirre, Univ. of Pennsylvania (United States); J. A. Brevik, H. M. Cho, National Institute of Standards and Technology (United States); R. Datta, Univ. of Michigan (United States); M. J. Devlin, B. Dober, Univ. of Pennsylvania (United States); D. Egan, J. Ford, P. Ford, National Radio Astronomy Observatory (United States); G. Hilton, J. Hubmayr, National Institute of Standards and Technology (United States); K. D. Irwin, Stanford Univ. (United States); B. S. Mason, P. Marganian, M. Mello, National Radio Astronomy Observatory (United States); J. J. McMahon, Univ. of Michigan (United States); T. Mroczkowski, U.S. Naval Research Lab. (United States); C. Romero, Stanford Univ. (United States) and Univ. of Virginia (United States); S. M. Stanchfield, Univ. of Pennsylvania (United States); C. Tucker, Cardiff Univ. (United Kingdom); L. Vale, National Institute of Standards and Technology (United States); S. White, M. Whitehead, National Radio Astronomy Observatory (United States); A. H. Young, Univ. of Pennsylvania (United States)

$91530 \mathrm{~K}$ The kilopixel array pathfinder project (KAPPa), a 16-pixel integrated heterodyne focal plane array: characterization of the single pixel prototype [9153-20]

C. H. Wheeler, C. E. Groppi, H. Mani, Arizona State Univ. (United States); P. McGarey, Univ. of Toronto Institute for Aerospace Studies (Canada); L. Kuenzi, Arizona State Univ. (United States); S. Weinreb, California Institute of Technology (United States); D. S. Russell, Jet Propulsion Lab. (United States); J. W. Kooi, California Institute of Technology (United States); A. W. Lichtenberger, Univ. of Virginia (United States); C. K. Walker, C. Kulesa, Steward Observatory, The Univ. of Arizona (United States) 
$9153 \mathrm{OL} \quad$ SWCam: the short wavelength camera for the CCAT observatory [9153-21]

G. J. Stacey, S. Parshley, T. Nikola, G. Cortes-Medellin, J. Schoenwald, G. Rajagopalan, M. D. Niemack, T. Jenness, P. Gallardo, B. Koopman, Cornell Univ. (United States); C. D. Dowell, California Institute of Technology (United States); P. K. Day, Jet Propulsion Lab. (United States); M. I. Hollister, California Institute of Technology (United States); A. Kovacs, California Institute of Technology (United States) and Univ. of Minnesota (United States); H. G. LeDuc, Jet Propulsion Lab. (United States); C. M. McKenney, California Institute of Technology (United States); R. M. Monroe, Jet Propulsion Lab. (United States); H. Yoshida, J. Zmuidzinas, L. J. Swenson, S. J. Radford, California Institute of Technology (United States); H. T. Nguyen, Jet Propulsion Lab. (United States); A. K. Mroczkowski, California Institute of Technology (United States); J. Glenn, J. Wheeler, P. Maloney, S. Brugger, Univ. of Colorado at Boulder (United States); J. D. Adams, SOFIA-USRA (United States); F. Bertoldi, R. Schaaf, Bonn Univ. (Germany); M. Halpern, D. Scott, G. Marsden, The Univ. of British Columbia (Canada); J. Sayers, California Institute of Technology (United States); S. Chapman, Dalhousie Univ. (Canada); J. D. Vieira, California Institute of Technology (United States)

9153 OM Status of SuperSpec: a broadband, on-chip millimeter-wave spectrometer [9153-22] S. Hailey-Dunsheath, California Institute of Technology (United States); E. Shirokoff, The Univ. of Chicago (United States); P. S. Barry, Cardiff Univ. (United Kingdom); C. M. Bradford, G. Chattopadhyay, P. Day, Jet Propulsion Lab. (United States); S. Doyle, Cardiff Univ. (United Kingdom); M. Hollister, California Institute of Technology (United States); A. Kovacs, Univ. of Minnesota, Twin Cities (United States); H. G. LeDuc, Jet Propulsion Lab. (United States); P. Mauskopf, Cardiff Univ. (United Kingdom) and Arizona State Univ. (United States); C. M. McKenney, R. Monroe, R. O'Brient, S. Padin, California Institute of Technology (United States); T. Reck, Jet Propulsion Lab. (United States); L. Swenson, California Institute of Technology (United States); C. E. Tucker, Cardiff Univ. (United Kingdom); J. Zmuidzinas, California Institute of Technology (United States) and Jet Propulsion Lab. (United States)

\section{SESSION 5 COHERENT DETECTOR TECHNOLOGY}

$9153 \mathrm{ON} \quad$ ALMA band $10(787-950 \mathrm{GHz})$ : summary of the production of 73 receivers and first light results [9153-23]

A. Gonzalez, Y. Fujii, K. Kaneko, M. Kroug, T. Kojima, K. Kuroiwa, A. Miyachi, National Astronomical Observatory of Japan (Japan); K. Makise, Z. Wang, National Institute of Information and Telecommunications Technology (Japan); S. Asayama, National Astronomical Observatory of Japan (Chile); Y. Uzawa, National Astronomical Observatory of Japan (Japan) and National Institute of Information and Telecommunications Technology (Japan)

$915300 \quad$ Local oscillator development for focal plane array and supra-THz astronomy receivers [9153-24]

M. Henry, B. Ellison, P. Aryathilaka, N. Brewster, P. Huggard, STFC Rutherford Appleton Lab. (United Kingdom); G. Yassin, Univ. of Oxford (United Kingdom); S. Withington, Cavendish Lab., Univ. of Cambridge (United Kingdom); D. Maier, Institute de Radioastronomie Millimétrique (France) 
9153 OP Argus: a 16-pixel millimeter-wave spectrometer for the Green Bank Telescope [9153-25] M. Sieth, K. Devaraj, P. Voll, S. Church, Stanford Univ. (United States) and Kavli Institute for Particle Astrophysics and Cosmology (United States); R. Gawande, K. Cleary,

A. C. S. Readhead, California Institute of Technology (United States); P. Kangaslahti, L. Samoska, T. Gaier, P. F. Goldsmith, Jet Propulsion Lab. (United States); A. I. Harris, Univ. of Maryland, College Park (United States); J. O. Gundersen, Univ. of Miami (United States);

D. Frayer, S. White, D. Egan, National Radio Astronomy Observatory (United States);

R. Reeves, CePIA, Univ. de Concepción (Chile)

$91530 Q \quad$ A multifeed S-band cryogenic receiver for the Sardinia Radio Telescope primary focus [9153-26]

G. Valente, G. Serra, F. Gaudiomonte, A. Ladu, T. Pisanu, P. Marongiu, A. Corongiu,

A. Melis, M. Buttu, D. Perrodin, INAF - Osservatorio Astronomico di Cagliari (Italy);

G. Montisci, G. Mazzarella, Univ. degli Studi di Cagliari (Italy); E. Egron, N. lacolina,

C. Tiburzi, V. Vacca, INAF - Osservatorio Astronomico di Cagliari (Italy)

9153 OR A 77-118 GHz resonance-free Septum polarizer [9153-27]

Y.-L. Chen, T. Chiveh, H.-F. Teng, National Taiwan Univ. (Taiwan)

\section{SESSION 6 KINETIC INDUCTANCE DETECTORS}

9153 OS Optimization of kinetic inductance detectors for millimeter and submillimeter wave detection [9153-28]

G. Coiffard, K. F. Schuster, Domaine Univ. (France); A. Monfardini, Institut NÉEL, CNRS (France) and Univ. de Grenoble (France); A. Adane, B. Barbier, C. Boucher, Domaine Univ. (France); M. Calvo, J. Goupy, Institut NÉEL, CNRS (France) and Univ. de Grenoble (France); S. Leclercq, Domaine Univ. (France); S. Pignard, Lab. des Matériaux et du Génie Physique (France)

9153 OT Performance of hybrid NbTiN-Al microwave kinetic inductance detectors as direct detectors for sub-millimeter astronomy [9153-29]

R. M. J. Janssen, Technische Univ. Delft (Netherlands); J. J. A. Baselmans, SRON Netherlands Institute for Space Research (Netherlands); A. Endo, Technische Univ. Delft (Netherlands);

L. Ferrari, S. J. C. Yates, SRON Netherlands Institute for Space Research (Netherlands); A. M. Baryshev, SRON Netherlands Institute for Space Research (Netherlands) and Kapteyn Astronomical Institute, Univ. of Groningen (Netherlands); T. M. Klapwijk, Technische Univ. Delft (Netherlands) and Moscow State Pedagogical Univ. (Russian Federation)

$9153 \mathrm{OW} \quad$ A LEKID-based CMB instrument design for large-scale observations in Greenland [9153-32] D. C. Araujo, Columbia Univ. (United States); P. A. R. Ade, Cardiff Univ. (United Kingdom); J. R. Bond, Canadian Institute for Theoretical Astrophysics, Univ. of Toronto (Canada); K. J. Bradford, Arizona State Univ. (United States); D. Chapman, Columbia Univ. (United States); G. Che, Arizona State Univ. (United States); P. K. Day, Jet Propulsion Lab. (United States); J. Didier, Columbia Univ. (United States); S. Doyle, Cardiff Univ. (United Kingdom); H. K. Eriksen, Univ. of Oslo (Norway); D. Flanigan, Columbia Univ. (United States); C. E. Groppi, Arizona State Univ. (United States); S. N. Hillbrand, Columbia Univ. (United States) and California State Univ. (United States); B. R. Johnson, G. Jones, M. Limon, A. D. Miller, Columbia Univ. (United States); P. Mauskopf, Arizona State Univ. (United States); H. McCarrick, Columbia Univ. (United States); T. Mroczkowski, U.S. Naval Research Lab. (United States); B. Reichborn-Kjennerud, B. Smiley, J. Sobrin, Columbia Univ. (United States); I. K. Wehus, Univ. of Oslo (Norway); J. Zmuidzinas, Jet Propulsion Lab. (United States) and California Institute of Technology (United States) 
9153 oY Characterization of the Atacama B-mode Search [9153-34]

S. M. Simon, Princeton Univ. (United States); S. Raghunathan, Univ. de Chile (Chile); J. W. Appel, Johns Hopkins Univ. (United States); D. T. Becker, National Institute of Standards and Technology (United States); L. E. Campusano, Univ. de Chile (Chile); H. M. Cho, National Institute of Standards and Technology (United States); T. Essinger-Hileman, Johns Hopkins Univ. (United States); S. P. Ho, Princeton Univ. (United States); K. D. Irwin, National Institute of Standards and Technology (United States) and Stanford Univ. (United States); N. Jarosik, A. Kusaka, Princeton Univ. (United States); M. D. Niemack, Cornell Univ. (United States); G. W. Nixon, Princeton Univ. (United States); M. R. Nolta, The Canadian Institute for Theoretical Astrophysics, Univ. of Toronto (Canada); L. A. Page, Princeton Univ. (United States); G. A. Palma, Univ. de Chile (Chile); L. P. Parker, Princeton Univ. (United States); J. L. Sievers, Univ. of KwaZulu-Natal (South Africa); S. T. Staggs, K. Visnjic, Princeton Univ. (United States)

915310 ACTPol: on-sky performance and characterization [9153-36]

E. Grace, Princeton Univ. (United States); J. Beall, National Institute of Standards and Technology (United States); J. R. Bond, Canadian Institute for Theoretical Astrophysics, Univ. of Toronto (Canada); H. M. Cho, National Institute of Standards and Technology (United States); R. Datta, Univ. of Michigan (United States); M. J. Devlin, Univ. of Pennsylvania (United States); R. Dünner, Pontificía Univ. Católica de Chile (Chile); A. E. Fox, National Institute of Standards and Technology (United States); P. Gallardo, Cornell Univ. (United States) and Pontificía Univ. Católica de Chile (Chile); M. Hasselfield, Princeton Univ. (United States) and The Univ. of British Columbia (Canada); S. Henderson, Cornell Univ. (United States); G. C. Hilton, National Institute of Standards and Technology (United States); A. D. Hincks, The Univ. of British Columbia (Canada); R. Hlozek, Princeton Univ. (United States); J. Hubmayr, National Institute of Standards and Technology (United States); K. Irwin, Stanford Univ. (United States); J. Klein, Univ. of Pennsylvania (United States); B. Koopman, Cornell Univ. (United States); D. Li, National Institute of Standards and Technology (United States); M. Lungu, Univ. of Pennsylvania (United States); L. Newburgh, Princeton Univ. (United States); J. P. Nibarger, National Institute of Standards and Technology (United States); M. D. Niemack, Cornell Univ. (United States); L. Maurin, Pontificía Univ. Católica de Chile (Chile); J. McMahon, Univ. of Michigan (United States); S. Naess, Univ. of Oxford (United Kingdom); L. A. Page, C. Pappas, Princeton Univ. (United States); B. L. Schmitt, Univ. of Pennsylvania (United States); J. Sievers, Univ. of KwaZulu-Natal (South Africa) and Canadian Institute for Theoretical Astrophysics, Univ. of Toronto (Canada); S. T. Staggs, Princeton Univ. (United States); R. Thornton, West Chester Univ. of Pennsylvania (United States); J. Van Lanen, National Institute of Standards and Technology (United States); E. J. Wollack, West Chester Univ. of Pennsylvania (United States)

915311 The performance of the bolometer array and readout system during the 2012/2013 flight of the $E$ and $B$ experiment (EBEX) [9153-37]

K. MacDermid, McGill Univ. (Canada); A. M. Aboobaker, Univ. of Minnesota (United States); P. Ade, Rutherford Appleton Lab. (United Kingdom); F. Aubin, Univ. of Minnesota, Twin Cities (United States); C. Baccigalupi, Scuola Internazionale Superiore di Studi Avanzati (Italy); K. Bandura, McGill Univ. (Canada); C. Bao, Univ. of Minnesota (United States); J. Borrill, Univ. of California, Berkeley (United States); D. Chapman, J. Didier, Columbia Univ. (United States); M. Dobbs, McGill Univ. (Canada) and Canadian Institute 
for Advanced Research (Canada); J. Grain, Institut d'Astrophysique Spatiale, Univ. Paris Sud (France); W. Grainger, Rutherford Appleton Lab. (United Kingdom); S. Hanany, Univ. of Minnesota (United States); K. Helson, Brown Univ. (United States); S. Hillbrand, Rutherford Appleton Lab. (United Kingdom); G. Hilton, H. Hubmayr, K. Irwin, National Institute of Standards and Technology (United States); B. Johnson, Rutherford Appleton Lab. (United Kingdom); A. Jaffe, Lawrence Berkeley National Lab. (United States); T. Jones, Univ. of Minnesota (United States); T. Kisner, Lawrence Berkeley National Lab. (United States); J. Klein, Univ. of Minnesota (United States); A. Korotkov, Brown Univ. (United States); A. Lee, Univ. of California, Berkeley (United States); L. Levinson, Weizmann Institute of Science (Israel); M. Limon, A. Miller, Columbia Univ. (United States); M. Milligan, Univ. of Minnesota (United States); E. Pascale, Rutherford Appleton Lab. (United Kingdom); K. Raach, Univ. of Minnesota (United States); B. Reichborn-Kjennerud, Columbia Univ. (United States); C. Reintsema, National Institute of Standards and Technology (United States); I. Sagiv, Weizmann Institute of Science (Israel); G. Smecher, McGill Univ. (Canada); R. Stompor, Lab. Astroparticule et Cosmologie, Univ. Paris Diderot (France); M. Tristram, Lab. de I'Accelerateur Lineaire, Univ. Paris-Sud 11 (France); G. Tucker, Brown Univ. (United States); B. Westbrook, Univ. of California, Berkeley (United States); K. Zilic, Univ. of Minnesota (United States)

915312 BICEP2 and Keck array: upgrades and improved beam characterization [9153-38] I. Buder, Harvard-Smithsonian Ctr. for Astrophysics (United States); P. A. R. Ade, Cardiff Univ. (United Kingdom); Z. Ahmed, Stanford Univ. (United States) and SLAC National Accelerator Lab., Kavli Institute for Particle Astrophysics and Cosmology (United States); R. W. Aikin, California Institute of Technology (United States); K. D. Alexander, Harvard-Smithsonian Ctr. for Astrophysics (United States); M. Amiri, The Univ. of British Columbia (Canada); D. Barkats, Joint ALMA Observatory (Chile); S. J. Benton, Univ. of Toronto (Canada); C. A. Bischoff, Harvard-Smithsonian Ctr. for Astrophysics (United States); J. J. Bock, California Institute of Technology (United States) and Jet Propulsion Lab. (United States); J. A. Bonetti, Jet Propulsion Lab. (United States); J. A. Brevik, California Institute of Technology (United States); E. Bullock, Univ. of Minnesota (United States); B. Burger, The Univ. of British Columbia (Canada); B. P. Crill, California Institute of Technology (United States) and Jet Propulsion Lab. (United States); G. Davis, The Univ. of British Columbia (Canada); C. D. Dowell, Jet Propulsion Lab. (United States); L. Duband, Commissariat a l'Energie Atomique (France); J. P. Filippini, California Institute of Technology (United States); S. Fliescher, Univ. of Minnesota (United States); S. R. Golwala, California Institute of Technology (United States); M. S. Gordon, Harvard-Smithsonian Ctr. for Astrophysics (United States); M. Halpern, M. Hasselfield, The Univ. of British Columbia (Canada); S. R. Hildebrandt, California Institute of Technology (United States) and Jet Propulsion Lab. (United States); G. C. Hilton, National Institute of Standards and Technology (United States); V. V. Hristov, H. Hui, California Institute of Technology (United States); K. D. Irwin, Stanford Univ. (United States), SLAC National Accelerator Lab., Kavli Institute for Particle Astrophysics and Cosmology (United States), and National Institute of Standards and Technology (United States); K. S. Karkare, Harvard-Smithsonian Ctr. for Astrophysics (United States); J. P. Kaufman, B. G. Keating, Univ. of California, San Diego (United States); S. Kefeli, California Institute of Technology (United States); S. A. Kernasovskiy, Stanford Univ. (United States); J. M. Kovac, Harvard-Smithsonian Ctr. for Astrophysic (United States); C. L. Kuo, Stanford Univ. (United States) and SLAC National Accelerator Lab., Kavli Institute for Particle Astrophysics and Cosmology (United States); E. M. Leitch, The Univ. of Chicago (United States); M. Lueker, P. Mason, California Institute of Technology (United States); K. G. Megerian, Jet Propulsion Lab. (United States); C. B. Netterfield, Univ. of Toronto (Canada) and Canadian Institute for Advanced Research (Canada); H. T. Nguyen, R. O'Brient, Jet Propulsion Lab. (United States); 
R. W. Ogburn IV, Stanford Univ. (United States) and SLAC National Accelerator Lab., Kavli Institute for Particle Astrophysics and Cosmology (United States); A. Orlando, Univ. of California, San Diego (United States); C. Pryke, Univ. of Minnesota (United States); C. D. Reintsema, National Institute of Standards and Technology (United States); S. Richter, Harvard-Smithsonian Ctr. for Astrophysics (United States); R. Schwarz, Univ. of Minnesota (United States); C. D. Sheehy, Univ. of Minnesota (United States) and Univ. of Chicago (United States); Z. K. Staniszewski, California Institute of Technology (United States) and Jet Propulsion Lab. (United States); R. V. Sudiwala, Cardiff Univ. (United Kingdom); G. P. Teply, California Institute of Technology (United States); K. L. Thompson, Stanford Univ. (United States) and SLAC National Accelerator Lab., Kavli Institute for Particle Astrophysics and Cosmology (United States); J. E. Tolan, Stanford Univ. (United States); A. D. Turner, Jet Propulsion Lab. (United States); A. G. Vieregg, Harvard-Smithsonian Ctr. for Astrophysics (United States) and The Univ. of Chicago (United States); A. C. Weber, Jet Propulsion Lab. (United States) and California Institute of Technology (United States); D. V. Wiebe, The Univ. of British Columbia (Canada); P. Wilson, Jet Propulsion Lab. (United States); C. L. Wong, Harvard-Smithsonian Ctr. for Astrophysics (United States); K. W. Yoon, Stanford Univ. (United States) and SLAC National Accelerator Lab., Kavli Institute for Particle Astrophysics and Cosmology (United States)

915313 Pre-flight integration and characterization of the SPIDER balloon-borne telescope [9153-39] A. S. Rahlin, Princeton Univ. (United States); P. A. R. Ade, Cardiff Univ. (United Kingdom); M. Amiri, The Univ. of British Columbia (Canada); S. J. Benton, Univ. of Toronto (Canada); J. J. Bock, California Institute of Technology (United States) and Jet Propulsion Lab. (United States); J. R. Bond, Canadian Institute for Theoretical Astrophysics, Inc., Univ. of Toronto (Canada) and Canadian Institute for Advanced Research (Canada); S. A. Bryan, Case Western Reserve Univ. (United States); H. C. Chiang, Univ. of KwaZulu-Natal (South Africa); C. R. Contaldi, Imperial College London (United Kingdom); B. P. Crill, O. Doré, California Institute of Technology (United States) and Jet Propulsion Lab. (United States); M. Farhang, Canadian Institute for Theoretical Astrophysics, Univ. of Toronto (Canada) and Univ. of Toronto (Canada); J. P. Filippini, California Institute of Technology (United States); L. M. Fissel, Univ. of Toronto (Canada) and Northwestern Univ. (United States); A. A. Fraisse, A. E. Gambrel, Princeton Univ. (United States); N. N. Gandilo, Univ. of Toronto (Canada); S. Golwala, California Institute of Technology (United States); J. E. Gudmundsson, Princeton Univ. (United States); M. Halpern, The Univ. of British Columbia (Canada) and Canadian Institute for Advanced Research (Canada); M. F. Hasselfield, Princeton Univ. (United States) and The Univ. of British Columbia (Canada); G. Hilton, National Institute of Standards and Technology (United States); W. A. Holmes, Jet Propulsion Lab. (United States); V. V. Hristov, California Institute of Technology (United States); K. D. Irwin, Stanford Univ. (United States), Kavli Institute for Particle Astrophysics and Cosmology, SLAC National Accelerator Lab. (United States), and National Institute of Standards and Technology (United States); W. C. Jones, Z. D. Kermish, Princeton Univ. (United States); C. L. Kuo, Stanford Univ. (United States) and SLAC National Accelerator Lab., Kavli Institute for Particle Astrophysics and Cosmology (United States); C. J. MacTavish, Kavli Institute for Cosmological Physics, The Univ. of Cambridge (United Kingdom); P. V. Mason, California Institute of Technology (United States); K. Megerian, Jet Propulsion Lab. (United States); L. Moncelsi, T. A. Morford, California Institute of Technology (United States); J. M. Nagy, Case Western Reserve Univ. (United States); C. B. Netterfield, Univ. of Toronto (Canada) and Canadian Institute for Advanced Research (Canada); R. O'Brient, California Institute of Technology (United States) and Jet Propulsion Lab. (United States); C. Reintsema, National Institute of Standards and Technology (United States); J. E. Ruhl, Case Western Reserve Univ. (United States); M. C. Runyan, Jet Propulsion Lab. (United States); J. A. Shariff, Univ. of Toronto (Canada); J. D. Soler, Institut d'Astrophysique Spatiale (France) and Univ. of Toronto 
(Canada); A. Trangsrud, Jet Propulsion Lab. (United States); C. Tucker, Cardiff Univ. (United Kingdom); R. S. Tucker, California Institute of Technology (United States); A. D. Turner, A. C. Weber, Jet Propulsion Lab. (United States); D. V. Wiebe, The Univ. of British Columbia (Canada); E. Y. Young, Princeton Univ. (United States)

\section{SESSION 8 OPTICS AND COMPONENTS}

915314 Refractive telescope systems for future cosmic microwave background polarimetry experiments [9153-40]

P. Hargrave, Cardiff Univ. (United Kingdom); G. Savini, Univ. College London (United Kingdom); M. Gradziel, N. Trappe, N. Tynan, M. Candotti, National Univ. of Ireland, Maynooth (Ireland); A. Challinor, Univ. of Cambridge (United Kingdom); S. Sørenson, TICRA (Denmark); P. Ade, R. Sudiwala, Cardiff Univ. (United Kingdom); M. van der Vorst, European Space Agency (Netherlands)

915316 Efficient algorithms for optimising the optical performance of profiled smooth walled horns for future CMB and Far-IR missions [9153-42]

D. McCarthy, N. Trappe, J. A. Murphy, C. O'Sullivan, M. Gradziel, S. Doherty, C. Bracken, N. Tynan, National Univ. of Ireland, Maynooth (Ireland); A. Polegre, European Space Agency (Netherlands); P. Huggard, Rutherford Appleton Lab. (United Kingdom)

915317 Development of large radii half-wave plates for CMB satellite missions [9153-43] G. Pisano, Cardiff Univ. (United Kingdom) and The Univ. of Manchester (United Kingdom); B. Maffei, M. W. Ng, V. Haynes, M. Brown, F. Noviello, The Univ. of Manchester (United Kingdom); P. de Bernardis, S. Masi, F. Piacentini, L. Pagano, M. Salatino, Univ. degli Studi di Roma La Sapienza (Italy); B. Ellison, M. Henry, Rutherford Appleton Lab. (United Kingdom); P. de Maagt, B. Shortt, European Space Agency (Netherlands)

915318 Polarization properties of a multi-moded feed horn for the Primordial Inflation Explorer mission [9153-44]

A. Kogut, D. J. Fixsen, R. S. Hill, P. Mirel, NASA Goddard Space Flight Ctr. (United States)

915319 Optical design for the 450, 350, and $200 \mu \mathrm{m}$ ArTeMiS camera [9153-45]

D. Dubreuil, J. Martignac, J. C. Toussaint, F. Visticot, C. Delisle, P. Gallais, J. Le-Pennec, T. Lerch, P. André, M. Lortholary, IRFU-CEA (France); B. Maffei, V. Haynes, The Univ. of Manchester (United Kingdom); N. Hurtado, Univ. zU Köln (Germany); G. Pisano, The Univ. of Manchester (United Kingdom); V. Revéret, L. Rodriguez, M. Talvard, IRFU-CEA (France)

\section{SESSION 9 MULTIPLEXING AND READOUT SYSTEMS}

$91531 \mathrm{~A}$ Digital frequency domain multiplexing readout electronics for the next generation of millimeter telescopes [9153-46]

A. N. Bender, J.-F. Cliche, T. de Haan, McGill Univ. (Canada); M. A. Dobbs, McGill Univ. (Canada) and Canadian Institute for Advanced Research (Canada); A. J. Gilbert, J. Montgomery, McGill Univ. (Canada); N. Rowlands, COM DEV Canada (Canada); G. M. Smecher, Three-Speed Logic, Inc. (Canada); K. Smith, A. Wilson, COM DEV Canada (Canada) 
9153 1B Optimization of cold resonant filters for frequency domain multiplexed readout of POLARBEAR-2 [9153-47]

K. Hattori, High Energy Accelerator Research Organization, KEK (Japan); Y. Akiba, The Graduate Univ. for Advanced Studies (Japan); K. Arnold, D. Barron, Univ. of California, San Diego (United States); A. Bender, M. Dobbs, T. de Haan, McGill Univ. (Canada); N. Harrington, Univ. of California, Berkeley (United States); M. Hasegawa, M. Hazumi, High Energy Accelerator Research Organization, KEK (Japan); W. L. Holzapfel, Univ. of California, Berkeley (United States); Y. Hori, High Energy Accelerator Research Organization, KEK (Japan); B. G. Keating, Univ. of California, San Diego (United States); A. T. Lee, Univ. of California, Berkeley (United States); J. Montgomery, McGill Univ. (Canada); H. Morii, High Energy Accelerator Research Organization, KEK (Japan); M. Myers, Univ. of California, Berkeley (United States); K. Rotermund, Dalhousie Univ. (Canada); I. Shirley, Univ. of California, Berkeley (United States); G. Smecher, Three-Speed Logic, Inc. (Canada); N. Stebor, Univ. of California, San Diego (United States); A. Suzuki, Univ. of California, Berkeley (United States); T. Tomaru, The Graduate Univ. for Advanced Studies (Japan)

$91531 \mathrm{E}$ The 160 TES bolometer read-out using FDM for SAFARI [9153-50]

R. A. Hijmering, R. den Hartog, A. J. van der Linden, M. Ridder, M. P. Bruijn, J. van der Kuur, B. J. van Leeuwen, P. van Winden, B. Jackson, Netherlands Institute for Space Research (Netherlands)

\section{SESSION 10 CMB INSTRUMENTS: NEW DEVELOPMENTS I}

9153 if The Simons Array: expanding POLARBEAR to three multi-chroic telescopes [9153-51] K. Arnold, N. Stebor, Univ. of California, San Diego (United States); P. A. R. Ade, Cardiff Univ. (United Kingdom); Y. Akiba, The Graduate Univ. for Advanced Studies (Japan); A. E. Anthony, Univ. of Colorado at Boulder (United States); M. Atlas, D. Barron, Univ. of California, San Diego (United States); A. Bender, McGill Univ. (Canada); D. Boettger, Univ. of California, San Diego (United States); J. Borrill, Lawrence Berkeley National Lab. (United States) and Univ. of California, Berkeley (United States); S. Chapman, Dalhousie Univ. (Canada); Y. Chinone, High Energy Accelerator Research Organization, KEK (Japan) and Univ. of California, Berkeley (United States); A. Cukierman, Univ. of California, Berkeley (United States); M. Dobbs, McGill Univ. (Canada); T. Elleflot, Univ. of California, San Diego (United States); J. Errard, Univ. of California, Berkeley (United States) and Lawrence Berkeley National Lab. (United States); G. Fabbian, AstroParticle et Cosmologie, CNRS, Univ. Paris Diderot (France), Observatoire de Paris, IRFU-CEA (France), and Scuola Internazionale Superiore di Studi Avanzati (Italy); C. Feng, Univ. of California, San Diego (United States); A. Gilbert, McGill Univ. (Canada); N. Goeckner-Wald, Univ. of California, Berkeley (United States); N. W. Halverson, Univ. of Colorado at Boulder (United States); M. Hasegawa, High Energy Accelerator Research Organization, KEK (Japan) and The Graduate Univ. for Advanced Studies (Japan); K. Hattori, High Energy Accelerator Research Organization, KEK (Japan); M. Hazumi, High Energy Accelerator Research Organization, KEK (Japan), The Graduate Univ. for Advanced Studies (Japan), and Kavli Institute for the Physics and Mathematics of the Universe, The Univ. of Tokyo (Japan); W. L. Holzapfel, Univ. of California, Berkeley (United States); Y. Hori, High Energy Accelerator Research Organization, KEK (Japan); Y. Inove, The Graduate Univ. for Advanced Studies (Japan); G. C. Jaehnig, Univ. of Colorado at Boulder (United States); A. H. Jaffe, Imperial College London (United Kingdom); N. Katayama, Kavli Institute for the Physics and Mathematics, The Univ. of Tokyo (Japan); B. Keating, Univ. of California, San Diego (United States); Z. Kermish, Princeton Univ. (United States); R. Keskitalo, Lawrence Berkeley National 
Lab. (United States); T. Kisner, Lawrence Berkeley National Lab. (United States) and Univ. of California, Berkeley (United States); M. Le Jeune, AstroParticle et Cosmologie, CNRS, Univ. Paris Diderot (France) and Observatoire de Paris, IRFU-CEA (France); A. T. Lee, Univ. of California, Berkeley (United States) and Lawrence Berkeley National Lab. (United States); E. M. Leitch, The Univ. of Chicago (United States) and Kavli Institute for Cosmological Physics, The Univ. of Chicago (United States); E. Linder, Lawrence Berkeley National Lab. (United States); F. Matsuda, Univ. of California, San Diego (United States); T. Matsumura, Institute of Space and Astronautical Science, Japan Aerospace Exploration Agency (Japan); X. Meng, Univ. of California, Berkeley (United States); N. J. Miller, NASA Goddard Space Flight Ctr. (United States); H. Morii, High Energy Accelerator Research Organization, KEK (Japan); M. J. Myers, Univ. of California, Berkeley (United States); M. Navaroli, Univ. of California, San Diego (United States); H. Nishino, Kavli Institute for the Physics and Mathematics, The Univ. of Tokyo (Japan); T. Okamura, High Energy Accelerator Research Organization, KEK (Japan); H. Paar, Univ. of California, San Diego (United States); J. Peloton, D. Poletti, AstroParticle et Cosmologie, CNRS, Univ. Paris Diderot (France) and Observatoire de Paris, IRFU-CEA (France); C. Raum, Univ. of California, Berkeley (United States); G. Rebeiz, Univ. of California, San Diego (United States); C. L. Reichardt, Univ. of Melbourne (Australia); P. L. Richards, Univ. of California, Berkeley (United States); C. Ross, K. M. Rotermund, Dalhousie Univ. (Canada); D. E. Schenck, Univ. of Colorado at Boulder (United States); B. D. Sherwin, I. Shirley, Univ. of California, Berkeley (United States); M. Sholl, Lawrence Berkeley National Lab. (United States); P. Siritanasak, Univ. of California, San Diego (United States); G. Smecher, Three-Speed Logic, Inc. (Canada); B. Steinbach, Univ. of California, Berkeley (United States); R. Stompor, AstroParticle et Cosmologie, CNRS, Univ. Paris Diderot (France) and Observatoire de Paris, IRFU-CEA (France); A. Suzuki, Univ. of California, Berkeley (United States); J. Suzuki, High Energy Accelerator Research Organization, KEK (Japan); S. Takada, National Institute for Fusion Science (Japan); S. Takakura, Osaka Univ. (Japan) and High Energy Accelerator Research Organization, KEK (Japan); T. Tomaru, High Energy Accelerator Research Organization, KEK (Japan); B. Wilson, A. Yadav, Univ. of California, San Diego (United States); O. Zahn, Lawrence Berkeley National Lab. (United States)

$91531 \mathrm{H} \quad$ PILOT: a balloon-borne experiment to measure the polarized FIR emission of dust grains in the interstellar medium [9153-53]

R. Misawa, J.-Ph. Bernard, Institut de Recherche en Astrophysique et Planétologie (France); P. Ade, Cardiff Univ. (United Kingdom); Y. André, Ctr. National des Etudes Spatiales (France); P. de Bernardis, Univ. degli Studi di Roma La Sapienza (Italy); M. Bouzit, M. Charra, B. Crane, J. P. Dubois, Institut d'Astrophysique Spatiale, CNES, Univ. Paris Sud (France); C. Engel, Institut de Recherche en Astrophysique et Planétologie (France); M. Griffin, P. Hargrave, Cardiff Univ. (United Kingdom); B. Leriche, Y. Longval, Institut d'Astrophysique Spatiale, CNES, Univ. Paris Sud (France); S. Maes, C. Marty, W. Marty, Institut de Recherche en Astrophysique et Planétologie (France); S. Masi, Univ. degli Studi di Roma La Sapienza (Italy); B. Mot, J. Narbonne, Institut de Recherche en Astrophysique et Planétologie (France); F. Pajot, Institut d'Astrophysique Spatiale, CNRS, Univ. Paris Sud (France); G. Pisano, Cardiff Univ. (United Kingdom); N. Ponthieu, Grenoble Univ. (France); I. Ristorcelli, Institut de Recherche en Astrophysique et Planétologie (France); L. Rodriguez, CEA, Saclay (France); G. Roudil, Institut de Recherche en Astrophysique et Planétologie (France); M. Salatino, Univ. degli Studi di Roma La Sapienza (Italy); G. Savini, C. Tucker, Cardiff Univ. (United Kingdom)

915311 CLASS: the cosmology large angular scale surveyor [9153-54] T. Essinger-Hileman, A. Ali, Johns Hopkins Univ. (United States); M. Amiri, The Univ. of British Columbia (Canada); J. W. Appel, Johns Hopkins Univ. (United States); D. Araujo, Columbia 
Univ. (United States); C. L. Bennett, F. Boone, M. Chan, Johns Hopkins Univ. (United States); H.-M. Cho, National Institute of Standards and Technology (United States); D. T. Chuss, F. Colazo, E. Crowe, K. Denis, NASA Goddard Space Flight Ctr. (United States); R. Dünner, Instituto de Astrofisica, Pontificia Univ. Católica de Chile (Chile); J. Eimer, D. Gothe, Johns Hopkins Univ. (United States); M. Halpern, The Univ. of British Columbia (Canada);

K. Harrington, Johns Hopkins Univ. (United States); G. Hilton, National Institute of Standards and Technology (United States); G. F. Hinshaw, The Univ. of British Columbia (Canada); C. Huang, Johns Hopkins Univ. (United States); K. Irwin, Stanford Univ. (United States); G. Jones, Columbia Univ. (United States); J. Karakla, Johns Hopkins Univ. (United States); A. J. Kogut, NASA Goddard Space Flight Ctr. (United States); D. Larson, Johns Hopkins Univ. (United States); M. Limon, Columbia Univ. (United States); L. Lowry, T. Marriage, N. Mehrle, Johns Hopkins Univ. (United States); A. D. Miller, Columbia Univ. (United States); N. Miller, S. H. Moseley, NASA Goddard Space Flight Ctr. (United States); G. Novak, Northwestern Univ. (United States); C. Reintsema, National Institute of Standards and Technology (United States); K. Rostem, T. Stevenson, D. Towner, K. U-Yen, NASA Goddard Space Flight Ctr. (United States); E. Wagner, D. Watts, Johns Hopkins Univ. (United States); E. Wollack, NASA Goddard Space Flight Ctr. (United States); Z. Xu, Johns Hopkins Univ. (United States); L. Zeng, Harvard-Smithsonian Ctr. for Astrophysics (United States)

$91531 \mathrm{~J}$ The cosmology large angular scale surveyor (CLASS): $\mathbf{3 8 - G H z}$ detector array of bolometric polarimeters [9153-55]

J. W. Appel, A. Ali, Johns Hopkins Univ. (United States); M. Amiri, The Univ. of British Columbia (Canada); D. Araujo, Columbia Univ. (United States); C. L. Bennet, F. Boone, M. Chan, Johns Hopkins Univ. (United States); H.-M. Cho, National Institute of Standards and Technology (United States); D. T. Chuss, F. Colazo, E. Crowe, K. Denis, NASA Goddard Space Flight Ctr. (United States); R. Dünner, Instituto de Astrofiscia, Pontificia Univ. Católica de Chile (Chile); J. Eimer, T. Essinger-Hileman, D. Gothe, Johns Hopkins Univ. (United States); M. Halpern, The Univ. of British Columbia (Canada); K. Harrington, Johns Hopkins Univ. (United States); G. Hilton, National Institute of Standards and Technology (United States); G. F. Hinshaw, The Univ. of British Columbia (Canada); C. Huang, Johns Hopkins Univ. (United States); K. Irwin, Stanford Univ. (United States); G. Jones, Columbia Univ. (United States); J. Karakula, Johns Hopkins Univ. (United States); A. J. Kogut, NASA Goddard Space Flight Ctr. (United States); D. Larson, Johns Hopkins Univ. (United States); M. Limon, Columbia Univ. (United States); L. Lowry, T. Marriage, N. Mehrle, Johns Hopkins Univ. (United States); A. D. Miller, Columbia Univ. (United States); N. Miller, S. H. Moseley, NASA Goddard Space Flight Ctr. (United States); G. Novak, Northwestern Univ. (United States); C. Reintsema, National Institute of Standards and Technology (United States); K. Rostem, Johns Hopkins Univ. (United States) and NASA Goddard Space Flight Ctr. (United States); T. Stevenson, D. Towner, K. U-Yen, NASA Goddard Space Flight Ctr. (United States); E. Wagner, D. Watts, Johns Hopkins Univ. (United States); E. Wollack, NASA Goddard Space Flight Ctr. (United States); Z. Xu, Johns Hopkins Univ. (United States); L. Zeng, HarvardSmithsonian Ctr. for Astrophysics (United States) 


\section{Part Two}

\section{SESSION 11 CMB INSTRUMENTS: NEW DEVELOPMENTS II}

$91531 \mathrm{~L}$ The Primordial Inflation Polarization Explorer (PIPER) [9153-57]

J. Lazear, Johns Hopkins Univ. (United States); P. A. R. Ade, Cardiff Univ. (United Kingdom);

D. Benford, NASA Goddard Space Flight Ctr. (United States); C. L. Bennett, Johns Hopkins Univ. (United States); D. T. Chuss, NASA Goddard Space Flight Ctr. (United States); J. L. Dotson, NASA Ames Research Ctr. (United States); J. R. Eimer, Johns Hopkins Univ. (United States); D. J. Fixsen, NASA Goddard Space Flight Ctr. (United States); M. Halpern, The Univ. of British Columbia (Canada); G. Hilton, National Institute of Standards and Technology (United States); J. Hinderks, NASA Goddard Space Flight Ctr. (United States) and Univ. of Michigan (United States); G. F. Hinshaw, The Univ. of British Columbia (Canada); K. Irwin, Stanford Univ. (United States); C. Jhabvala, NASA Goddard Space Flight Ctr. (United States); B. Johnson, Columbia Univ. (United States); A. Kogut, NASA Goddard Space Flight Ctr. (United States); L. Lowe, NASA Goddard Space Flight Ctr. (United States) and Wyle STE (United States); J. J. McMahon, Univ. of Michigan (United States); T. M. Miller, NASA Goddard Space Flight Ctr. (United States); P. Mirel, NASA Goddard Space Flight Ctr. (United States) and Wyle STE (United States); S. H. Moseley, NASA Goddard Space Flight Ctr. (United States); S. Rodriguez, NASA Goddard Space Flight Ctr. (United States) and ADNET Systems, Inc. (United States); E. Sharp, NASA Goddard Space Flight Ctr. (United States); J. G. Staguhn, Johns Hopkins Univ. (United States) and NASA Goddard Space Flight Ctr. (United States); E. R. Switzer, NASA Goddard Space Flight Ctr. (United States); C. E. Tucker, Cardiff Univ. (United Kingdom); A. Weston, NASA Goddard Space Flight Ctr. (United States) and ADNET Systems, Inc. (United States); E. J. Wollack, NASA Goddard Space Flight Ctr. (United States)

9153 IN BICEP3: a 95GHz refracting telescope for degree-scale CMB polarization [9153-59] Z. Ahmed, Stanford Univ. (United States) and Kavli Institute for Particle Astrophysics and Cosmology, SLAC National Accelerator Lab. (United States); M. Amiri, The Univ. of British Columbia (Canada); S. J. Benton, Univ. of Toronto (Canada); J. J. Bock, California Institute of Technology (United States) and Jet Propulsion Lab. (United States); R. Bowens-Rubin, I. Buder, Harvard-Smithsonian Ctr. for Astrophysics (United States); E. Bullock, Univ. of Minnesota (United States); J. Connors, Harvard-Smithsonian Ctr. for Astrophysics (United States); J. P. Filippini, California Institute of Technology (United States); J. A. Grayson, Stanford Univ. (United States) and Kavli Institute for Particle Astrophysics and Cosmology, SLAC National Accelerator Lab. (United States); M. Halpern, The Univ. of British Columbia (Canada); G. C. Hilton, National Institute of Standards and Technology (United States); V. V. Hristov, H. Hui, California Institute of Technology (United States); K. D. Irwin, J. Kang, Stanford Univ. (United States) and Kavli Institute for Particle Astrophysics and Cosmology, SLAC National Accelerator Lab. (United States); K. S. Karkare, Harvard-Smithsonian Ctr. for Astrophysics (United States); E. Karpel, Stanford Univ. (United States); J. M. Kovac, HarvardSmithsonian Ctr. for Astrophysics (United States); C. L. Kuo, Stanford Univ. (United States) and Kavli Institute for Particle Astrophysics and Cosmology, SLAC National Accelerator Lab. (United States); C. B. Netterfield, Univ. of Toronto (Canada); H. T. Nguyen, Jet Propulsion Lab. (United States); R. O'Brient, California Institute of Technology (United States); R. W. Ogburn IV, Stanford Univ. (United States) and Kavli Institute for Particle Astrophysics and Cosmology, SLAC National Accelerator Lab. (United States); C. Pryke, Univ. of Minnesota (United States); C. D. Reintsema, National Institute of Standards and Technology (United States); S. Richter, Harvard-Smithsonian Ctr. for Astrophysics (United States); K. L. Thompson, Stanford Univ. (United States) and Kavli Institute for Particle 
Astrophysics and Cosmology, SLAC National Lab. (United States); A. D. Turner, Jet Propulsion Lab. (United States); A. G. Vieregg, The Univ. of Chicago (United States); W. L. K. Wu, K. W. Yoon, Stanford Univ. (United States) and Kavli Institute for Particle Astrophysics and Cosmology, SLAC National Lab. (United States)

9153 IP SPT-3G: a next-generation cosmic microwave background polarization experiment on the South Pole telescope [9153-61]

B. A. Benson, Fermi National Accelerator Lab. (United States), Kavli Institute for Cosmological Physics, The Univ. of Chicago (United States), and The Univ. of Chicago (United States); P. A. R. Ade, Cardiff Univ. (United Kingdom); Z. Ahmed, S. W. Allen, Kavli Institute for Particle Astrophysics and Cosmology, Stanford Univ. (United States), Stanford Univ. (United States), and SLAC National Accelerator Lab. (United States); K. Arnold, Univ. of California, San Diego (United States); J. E. Austermann, Univ. of Colorado at Boulder (United States); A. N. Bender, McGill Univ. (Canada); L. E. Bleem, Kavli Institute for Cosmological Physics, The Univ. of Chicago (United States) and Argonne National Lab. (United States); J. E. Carlstrom, Kavli Institute for Cosmological Physics, The Univ. of Chicago (United States), The Univ. of Chicago (United States), and Argonne National Lab. (United States); C. L. Chang, Argonne National Lab. (United States), Kavli Institute for Cosmological Physics, The Univ. of Chicago (United States), and The Univ. of Chicago (United States); H. M. Cho, SLAC National Accelerator Lab. (United States); J. F. Cliche, McGill Univ. (Canada); T. M. Crawford, Kavli Institute for Cosmological Physics, The Univ. of Chicago (United States) and The Univ. of Chicago (United States); A. Cukierman, Univ. of California, Berkeley (United States); T. de Haan, McGill Univ. (Canada); M. A. Dobbs, McGill Univ. (Canada) and Canadian Institute for Advanced Research (Canada); D. Dutcher, Kavli Institute for Cosmological Physics, The Univ. of Chicago (United States) and The Univ. of Chicago (United States); W. Everett, Univ. of Colorado at Boulder (United States); A. Gilbert, McGill Univ. (Canada); N. W. Halverson, Univ. of Colorado at Boulder (United States); D. Hanson, McGill Univ. (Canada); N. L. Harrington, Univ. of California, Berkeley (United States); K. Hattori, High Energy Accelerator Research Organization, KEK (Japan); J. W. Henning, Univ. of Colorado at Boulder (United States); G. C. Hilton, National Institute of Standards and Technology (United States); G. P. Holder, McGill Univ. (Canada) and Canadian Institute for Advanced Research (Canda); W. L. Holzapfel, Univ. of California, Berkeley (United States); K. D. Irwin, Kavli Institute for Particle Astrophysics and Cosmology, Stanford Univ. (United States), Stanford Univ. (United States), and SLAC National Accelerator Lab. (United States); R. Keisler, Kavli Institute for Cosmological Physics, Stanford Univ. (United States) and Stanford Univ. (United States); L. Knox, Univ. of California, Davis (United States); D. Kubik, Fermi National Accelerator Lab. (United States); C. L. Kuo, Kavli Institute for Particle Astrophysics and Cosmology, Stanford Univ. (United States), Stanford Univ. (United States), and SLAC National Accelerator Lab. (United States); A. T. Lee, Univ. of California, Berkeley (United States) and Lawrence Berkeley National Lab. (United States); E. M. Leitch, Kavli Institute for Cosmological Physics, The Univ. of Chicago (United States) and The Univ. of Chicago (United States); D. Li, National Institute of Standards and Technology (United States); M. McDonald, Kavli Institute for Astrophysics and Space Research, Massachusetts Institute of Technology (United States); S. S. Meyer, Kavli Institute for Cosmological Physics, The Univ. of Chicago (United States) and The Univ. of Chicago (United States); J. Montgomery, McGill Univ. (Canada); M. Myers, Univ. of California, Berkeley (United States); T. Natoli, Kavli Institute for Cosmological Physics, The Univ. of Chicago (United States) and The Univ. of Chicago (United States); H. Nguyen, Fermi National Accelerator Lab. (United States); V. Novosad, Argonne National Lab. (United States); S. Padin, California Institute of Technology (United States); Z. Pan, Kavli Institute for Cosmological Physics, The Univ. of Chicago (United States) and The Univ. of Chicago 
(United States); J. Pearson, Argonne National Lab. (United States); C. Reichardt, Univ. of Melbourne (Australia) and Univ. of California, Berkeley (United States); J. E. Ruhl, B. R. Saliwanchik, Case Western Reserve Univ. (United States); G. Simard, McGill Univ. (Canada); G. Smecher, Three-Speed Logic, Inc. (Canada); J. T. Sayre, Case Western Reserve Univ. (United States); E. Shirokoff, Kavli Institute for Cosmological Physics, The Univ. of Chicago (United States) and The Univ. of Chicago (United States); A. A. Stark, HarvardSmithsonian Ctr. for Astrophysics (United States); K. Story, Kavli Institute for Cosmological Physics, The Univ. of Chicago (United States) and The Univ. of Chicago (United States); A. Suzuki, Univ. of California, Berkeley (United States); K. L. Thompson, Kavli Institute for Particle Astrophysics and Cosmology, Stanford Univ. (United States), Stanford Univ. (United States), and SLAC National Accelerator Lab. (United States); C. Tucker, Cardiff Univ. (United Kingdom); K. Vanderlinde, Univ. of Toronto (Canada); J. D. Vieira, Univ. of Illinois (United States); A. Vikhlinin, Harvard-Smithsonian Ctr. for Astrophysics (United States); G. Wang, V. Yefremenko, Argonne National Lab. (United States); K. W. Yoon, Kavli Institute for Particle Astrophysics and Cosmology, Stanford Univ. (United States), Stanford Univ. (United States), and SLAC National Accelerator Lab. (United States)

\section{SESSION 12 TERAHERTZ TECHNOLOGY}

$91531 Q \quad$ Development of hot-electron THz bolometric mixers using $\mathbf{M g B}_{2}$ thin films [9153-62] D. Cunnane, J. Kawamura, B. S. Karasik, Jet Propulsion Lab. (United States); M. A. Wolak, X. X. Xi, Temple Univ. (United States)

9153 IR A 4.7THz heterodyne receiver for a balloon borne telescope [9153-63]

D. J. Hayton, SRON Netherlands Institute for Space Research (Netherlands);

J. L. Kloosterman, The Univ. of Arizona (United States); Y. Ren, Technische Univ. Delft (Netherlands); T. Y. Kao, Massachusetts Institute of Technology (United States); J. R. Gao, SRON Netherlands Institute for Space Research (Netherlands) and Technical Univ. Delft (Netherlands); T. M. Klapwijk, Technische Univ. Delft (Netherlands); Q. Hu, Massachusetts Institute of Technology (United States); C. K. Walker, Steward Observatory, Univ. of Arizona (United States); J. L. Reno, Sandia National Labs. (United States)

9153 IU CNES detector developments from far-infrared to $\mathrm{mm}$ : status and roadmap [9153-66] H. Geoffray, Ctr. National d'Études Spatiales (France); A. Monfardini, Institut NÉEL (France); S. Marnieros, CSNSM (France); M. Piat, Lab. AstroParticule et Cosmologie (France); L. Rodriguez, Commissariat à l'Énergie Atomique (France); A. Bardoux, Ctr. National d'Études Spatiales (France)

\section{SESSION 13 EMERGING CONCEPTS AND NEW INSTRUMENTS}

$91531 \mathrm{~V}$ Instrumentation for single-dish observations with The Greenland Telescope [9153-67] P. K. Grimes, Smithsonian Astrophysical Observatory (United States); K. Asada, Institute of Astronomy and Astrophysics, Academia Sinica (Taiwan); R. Blundell, R. Burgos, Smithsonian Astrophysical Observatory (United States); H.-H. Chang, M. T. Chen, Institute of Astronomy and Astrophysics, Academia Sinica (Taiwan); D. Goldie, Cavendish Lab., Univ. of Cambridge (United Kingdom); C. Groppi, Arizona State Univ. (United States); C. C. Han, P. T. P. Ho, Y. D. Huang, M. Inove, D. Kubo, P. Koch, Institute of Astronomy and Astrophysics, Academia Sinica (Taiwan); J. Leech, Univ. of Oxford (United Kingdom); E. de Lera Acedo, Cavendish Lab., Univ. of Cambridge (United Kingdom); P. Martin-Cocher, H. Nishioka, 
M. Nakamura, S. Matsushita, Institute of Astronomy and Astrophysics, Academia Sinica (Taiwan); S. N. Paine, N. Patel, Smithsonian Astrophysical Observatory (United States); P. Raffin, W. Snow, Institute of Astronomy and Astrophysics, Academia Sinica (Taiwan); T. K. Sridharan, Smithsonian Astrophysical Observatory (United States); R. Srinivasan, Institute of Astronomy and Astrophysics, Academia Sinica (Taiwan); C. N. Thomas, Cavendish Lab., Univ. of Cambridge (United Kingdom); E. Tong, Smithsonian Astrophysical Observatory (United States); M.-J. Wang, Institute of Astronomy and Astrophysics, Academia Sinica (Taiwan); C. Wheeler, Arizona State Univ. (United States); S. Withington, Cavendish Lab., Univ. of Cambridge (United Kingdom); G. Yassin, Univ. of Oxford (United Kingdom); L.-Z. Zeng, Smithsonian Astrophysical Observatory (United States)

$91531 \mathrm{~W}$ The TIME-Pilot intensity mapping experiment [9153-68]

A. T. Crites, J. J. Bock, California Institute of Technology (United States); C. M. Bradford, Jet Propulsion Lab. (United States); T. C. Chang, Institute of Astronomy and Astrophysics (Taiwan); A. R. Cooray, Univ. of California, Irvine (United States); L. Duband, Commissariat à I'Énergie Atomique (France); Y. Gong, Univ. of California, Irvine (United States); S. HaileyDunsheath, J. Hunacek, California Institute of Technology (United States); P. M. Koch, C. T. Li, Institute of Astronomy and Astrophysics (Taiwan); R. C. O'Brient, California Institute of Technology (United States); T. Prouve, Commissariat à l'Energie Atomique (France); E. Shirokoff, The Univ. of Chicago (United States); M. B. Silva, CENTRA (Portugal); Z. Staniszewski, California Institute of Technology (United States); B. Uzgil, Univ. of Pennsylvania (United States); M. Zemcov, California Institute of Technology (United States)

9153 IY X-Spec: a multi-object trans-millimeter-wave spectrometer for CCAT [9153-70] C. M. Bradford, Jet Propulsion Lab. (United States); S. Hailey-Dunsheath, California Institute of Technology (United States); E. Shirokoff, California Institute of Technology (United States) and Kavli Institute for Cosmological Physics, The Univ. of Chicago (United States);

M. Hollister, C. M. McKenney, California Institute of Technology (United States); H. G. LeDuc, T. Reck, Jet Propulsion Lab. (United States); S. C. Chapman, A. Tikhomirov, Dalhousie Univ. (Canada); T. Nikola, Cornell Univ. (United States); J. Zmuidzinas, California Institute of Technology (United States)

$915312 \quad$ KPAF (K-band phased array feed) instrument concept [9153-71] L. Locke, NRC - Herzburg Institute of Astrophysics (Canada) and Univ. of Victoria (Canada); S. Claude, NRC - Herzburg Institute of Astrophysics (Canada); J. Bornemann, Univ. of Victoria (Canada); D. Henke, J. Di Francesco, F. Jiang, D. Garcia, I. Wevers, P. Niranjanan, NRC - Herzburg Institute of Astrophysics (Canada)

915320 A quasioptical steering system for the CCAT/XSPEC submillimeter multi-object spectrometer [9153-135]

S. C. Chapman, A. Tikhomirov, Dalhousie Univ. (Canada); C. M. Bradford,

S. Hailey-Dunsheath, California Institute of Technology (United States)

\section{POSTER SESSION}

915321 Design of antenna-coupled lumped-element titanium nitride KIDs for long-wavelength multi-band continuum imaging [9153-31]

C. Ji, California Institute of Technology (United States); A. Beyer, Jet Propulsion Lab. (United States); S. Golwala, J. Sayers, California Institute of Technology (United States) 
915322 SCUBA-2 Fourier transform spectrometer (FTS-2) commissioning results [9153-72]

B. G. Gom, D. A. Naylor, Univ. of Lethbridge (Canada); P. Friberg, G. S. Bell, D. Bintley, Joint Astronomy Ctr. (United States); S. Abdelazim, M. Sherwood, Univ. of Lethbridge (Canada)

915323 The spectral response of the SCUBA-2 850- and 450-micron photometric bands [9153-73] D. A. Naylor, B. G. Gom, S. Abdelazim, Univ. of Lethbridge (Canada); P. Friberg, D. Bintley, Joint Astronomy Ctr. (United States); W. S. Holland, M. J. Maclntosh, UK Astronomy Technology Ctr. (United Kingdom); P. A. R. Ade, C. E. Tucker, Cardiff Univ. (United Kingdom)

915324 Cryogenic system for the ArTeMiS large sub millimeter camera [9153-75]

E. Ercolani, Univ. Grenoble (France); J. Relland, IRFU-CEA (France); L. Clerc, L. Duband, T. Jourdan, Univ. Grenoble (France); M. Talvard, J. Le Pennec, J. Martignac, F. Visticot, Lab. AIM, CNRS, Univ. Paris Diderot (France) and IRFU-CEA (France)

915325 Spectral definition of the ArTeMiS instrument [9153-76]

V. Haynes, B. Maffei, G. Pisano, The Univ. of Manchester (United Kingdom); D. Dubreuil, C. Delisle, J. Le Pennec, CEA-Saclay (France); N. Hurtado, Univ. zu Köln (Germany)

915326 Preliminary design of the wavefront front sensor for CCAT [9153-77]

D. Naylor, Univ. of Lethbridge (Canada); B. Gom, Blue Sky Spectroscopy Inc. (Canada); M. Leclerc, M. Legros, INO (Canada); S. Padin, California Institute of Technology (United States); E. Serabyn, Jet Propulsion Lab. (United States)

915327 Optics and cryogenics for the 1.1 THz multi-pixel heterodyne receiver for APEX [9153-78] N. Hurtado, U. U. Graf, H. Adams, C. E. Honingh, K. Jacobs, P. Pütz, Kölner Observatorium für Submm Astronomie, Univ. zu Köln (Germany); R. Güsten, Max-Planck-Institut für Radioastronomie (Germany); J. Stutzki, Kölner Observatorium für Submm Astronomie, Univ. zU Köln (Germany)

915328 Conceptual design of a cryogenic test bench system for millimeter wavelength detectors [9153-79]

S. Ventura, D. Ferrusca, E. Ibarra-Medel, Instituto Nacional de Astrofísica, Óptica y Electrónica (Mexico)

915329 Hacking for astronomy: can 3D printers and open-hardware enable low-cost submillimeter instrumentation? [9153-82]

C. Ferkinhoff, Max-Planck-Institut für Astronomie (Germany)

$91532 \mathrm{~A}$ The opto-cryo-mechanical design of the short wavelength camera for the CCAT Observatory [9153-83]

S. C. Parshley, Cornell Univ. (United States); J. Adams, Cornell Univ. (United States) and SOFIA-USRA (United States); T. Nikola, G. J. Stacey, Cornell Univ. (United States)

9153 2C An automated test system for terahertz receiver characterization [9153-85] L. C. Kuenzi, C. E. Groppi, C. H. Wheeler, H. Mani, Arizona State Univ. (United States)

9153 2D The software-based polarization spectrometer PolariS [9153-86]

S. Kameno, Joint ALMA Observatory (Chile); I. Mizuno, Kagoshima Univ. (Japan) and Nobeyama Radio Observatory (Japan); F. Nakamura, National Astronomical Observatory of Japan (Japan); M. Kuroo, Shoyo High School (Japan); A. Kano, Kagoshima Univ. (Japan); N. Kawaguchi, K. M. Shibata, National Astronomical Observatory of Japan 
(Japan); N. Kuno, S. Takano, Nobeyama Radio Observatory (Japan); S. Kuji, National Astronomical Observatory of Japan (Japan)

$91532 \mathrm{E} \quad$ A digital sideband-separating receiver for the millimeter band [9153-87]

R. Rodríguez, R. Finger, F. P. Mena, L. Bronfman, E. A. Michael, Univ. de Chile (Chile)

$91532 \mathrm{~F} \quad$ A 16-channel flex circuit for cryogenic microwave signal transmission [9153-88]

P. McGarey, Univ. of Toronto (Canada); H. Mani, C. Wheeler, C. Groppi, Arizona State Univ. (United States)

$91532 \mathrm{G}$ Proof of concept of a photonic sideband-separating receiver for submm-wave applications [9153-89]

J. A. Castillo, ALMA Observatory (Chile); R. Roman, F. P. Mena, E. A. Michael, Univ. de Chile (Chile)

$91532 \mathrm{H}$ Development of band-1 receiver cartridge for Atacama Large Millimeter/submillimeter Array (ALMA) [9153-90]

Y.-J. Hwang, C.-C. Chiong, T. Huang, Y.-F. Kuo, C.-C. Lin, C.-T. Ho, H. Chuang, Institute of Astronomy and Astrophysics, Academia Sinica (Taiwan); M. Pospieszalski, National Radio Astronomy Observatory (United States); D. Henke, S. Claude, NRC - Herzberg Institute of Astrophysics (Canada); N. Reyes, R. Finger, Univ. de Chile (Chile)

$915321 \quad$ Detecting loss of coherence based on telescope calibration results in ALMA [9153-91] A. Saez, Joint ALMA Observatory (Chile); A. Tejada, National Radio Astronomy Observatory (United States); D. Herrera, J. Sepulveda, Joint ALMA Observatory (Chile)

9153 2J A 3mm band SIS receiver for the Sardinia Radio Telescope [9153-92] A. Ladu, T. Pisanu, INAF - Osservatorio Astronomico di Cagliari (Italy); A. Navarrini, IRAM Institut de Radio Astronomie Millimétrique (France); P. Marongiu, G. Valente, INAF Osservatorio Astronomico di Cagliari (Italy)

$91532 \mathrm{~K} \quad$ Measuring the first two statistics moments using the Correlator resources [9153-93] A. Saez, D. Herrera, J. Sepulveda, Joint ALMA Observatory (Chile)

$91532 \mathrm{~L}$ Efficient spurious signal detection and mitigation in single-dish radio spectroscopy [9153-94]

S. Kameno, Joint ALMA Observatory (Chile); M. Miccolis, Joint ALMA Observatory (Chile) and National Ecological Observatory Network (United States); M. Sugimoto, T. Nakos, Joint ALMA Observatory (Chile)

$91532 \mathrm{M}$ An infrastructure for multi back-end observations with the Sardinia Radio Telescope [9153-95]

A. Melis, G. Valente, A. Tarchi, INAF - Osservatorio Astronomico di Cagliari (Italy); M. Barbaro, Univ. degli Studi di Cagliari (Italy); R. Concu, A. Corongiu, F. Gaudiomonte, C. Migoni, INAF - Osservatorio Astronomico di Cagliari (Italy); G. Montisci, Univ. degli Studi di Cagliari (Italy); S. Poppi, A. Trois, INAF - Osservatorio Astronomico di Cagliari (Italy)

$91532 \mathrm{~N}$ Comparison of cryogenic W band low noise amplifier based on different III-V HEMT foundry process and technologies [9153-98]

L. Valenziano, INAF - Instituto di Astrofisica Spaziale e Fisica Cosmica (Italy); M. Zannoni, Univ. degli Studi di Milano-Bicocca (Italy); S. Mariotti, INAF - Istituto di Radioastronomia (Italy); A. Cremonini, SKA Organisation (Italy); A. De Rosa, INAF - Instituto di Astrofisica 
Spaziale e Fisica Cosmica (Italy); S. Banfi, A. Baù, M. Gervasi, Univ. degli Studi di MilanoBicocca (Italy); E. Limiti, Univ. degli Studi di Roma "Tor Vergata" (Italy); A. Passerini, Univ. degli Studi di Milano-Bicocca (Italy); F. Schiavone, INAF - Instituto di Astrofisica Spaziale e Fisica Cosmica (Italy)

915320 A single-chip dual-band switched SIS mixer [9153-99]

B. K. Tan, Univ. of Oxford (United Kingdom) and Wawasan Open Univ. (Malayisia); G. Yassin, Univ. of Oxford (United Kingdom); S. Withington, Cavendish Lab., Univ. of Cambridge (United Kingdom)

91532 P Developments of wide field submillimeter optics and lens antenna-coupled MKID cameras [9153-100] Y. Sekimoto, National Astronomical Observatory of Japan (Japan) and The Univ. of Tokyo (Japan); T. Nitta, National Astronomical Observatory of Japan (Japan), Univ. of Tsukuba (Japan), and Japan Society for the Promotion of Science (Japan); K. Karatsu, National Astronomical Observatory of Japan (Japan); M. Sekine, S. Sekiguchi, T. Okada, S. Shu, National Astronomical Observatory of Japan (Japan) and The Univ. of Tokyo (Japan); T. Noguchi, National Astronomical Observatory of Japan (Japan); M. Naruse, National Astronomical Observatory of Japan (Japan) and Saitama Univ. (Japan); K. Mitsui, N. Okada, T. Tsuzuki, A. Dominjon, H. Matsuo, National Astronomical Observatory of Japan (Japan)

$91532 Q \quad H i g h-e n e r g y$ interactions in kinetic inductance detectors arrays [9153-101] A. D'Addabbo, Institut NÉEL (France), CNRS, Univ. Joseph Fourier (France), and Univ. degli Studi di Roma La Sapienza (Italy); M. Calvo, J. Goupy, Institut NÉEL (France) and CNRS, Univ. Joseph Fourier (France); A. Benoit, Univ. degli Studi di Roma La Sapienza (Italy); O. Bourrion, A. Catalano, J. F. Macias-Perez, Lab. de Physique Subatomique et de Cosmologie, CNRS, Univ. de Grenoble (France); A. Monfardini, Institut NÉEL (France) and CNRS, Univ. Joseph Fourier (France)

$91532 R$ Design, fabrication, and testing of lumped element kinetic inductance detectors for $\mathbf{3} \mathbf{~ m m}$ CMB Observations [9153-102]

A. E. Lowitz, Univ. of Wisconsin-Madison (United States); A.-D. Brown, T. R. Stevenson, NASA Goddard Space Flight Ctr. (United States); P. T. Timbie, Univ. of Wisconsin-Madison (United States); E. J. Wollack, NASA Goddard Space Flight Ctr. (United States)

$91532 T \quad$ Fabrication of 721-pixel silicon lens array of an MKID camera [9153-104]

K. Mitsui, National Astronomical Observatory of Japan (Japan); T. Nitta, National Astronomical Observatory of Japan (Japan) and Univ. of Tsukuba (Japan); N. Okada, National Astronomical Observatory of Japan (Japan); Y. Sekimoto, National Astronomical Observatory of Japan (Japan) and The Univ. of Tokyo (Japan); K. Karatsu, National Astronomical Observatory of Japan (Japan); S. Sekiguchi, M. Sekine, National Astronomical Observatory of Japan (Japan) and The Univ. of Tokyo (Japan); T. Noguchi, National Astronomical Observatory of Japan (Japan)

$91532 \mathrm{U}$ Design of wide-field Nasmyth optics for a submillimeter camera [9153-105] T. Tsuzuki, National Astronomical Observatory of Japan (Japan); T. Nitta, National Astronomical Observatory of Japan (Japan) and Univ. Of Tsukuba (Japan); H. Imada, M. Seta, N. Nakai, Univ. of Tsukuba (Japan); S. Sekiguchi, National Astronomical Observatory of Japan (Japan) and The Univ. of Tokyo (Japan); Y. Sekimoto, National Astronomical Observatory of Japan (Japan) 
$91532 \mathrm{~V}$ Optical modelling of far-infrared astronomical instrumentation exploiting multimode horn antennas [9153-106]

C. O'Sullivan, J. A. Murphy, I. Mc Auley, D. Wilson, M. L. Gradziel, N. Trappe, F. Cahill, T. Peacocke, National Univ. of Ireland, Maynooth (Ireland); G. Savini, Univ. College London (United Kingdom); K. Ganga, Lab. AstroParticule et Cosmologie (France)

9153 2W High performance WR-1.5 corrugated horn based on stacked rings [9153-107] B. Maffei, The Univ. of Manchester (United Kingdom); A. von Bieren, E. de Rijk, SWISSto 12 SA (Switzerland); J.-P. Ansermet, Ecole Polytechnique Fédérale de Lausanne (Switzerland); G. Pisano, S. Legg, The Univ. of Manchester (United Kingdom); A. Macor, SWISStol2 SA (Switzerland)

$91532 X \quad$ New RF data on ECCOSORB CR/MF absorber [9153-108] L. Valenziano, INAF - Istituto Nazionale di AstroFisica Spaziale e Fisica Cosmica (Italy); O. A. Peverini, Istituto di Elettronica, Computer e Ingegneria delle Telecomunicazioni, CNR (Italy); M. Zannoni, Univ. degli Studi di Milano-Bicocca (Italy); R. Tascone, G. Addamo, G. Virone, M. Lumia, Istituto di Elettronica, Computer e Ingegneria delle Telecomunicazioni, CNR (Italy); S. Mariotti, INAF - Istituto di Radioastronomia (Italy); A. De Rosa, INAF - Istituto Nazionale di AstroFisica Spaziale e Fisica Cosmica (Italy)

$915322 \quad$ Antireflection coatings for submillimeter silicon lenses [9153-111] J. D. Wheeler, Univ. of Colorado at Boulder (United States); B. Koopman, P. Gallardo, Cornell Univ. (United States); P. R. Maloney, S. Brugger, Univ. of Colorado at Boulder (United States); G. Cortes-Medellin, Cornell Univ. (United States); R. Datta, Univ. of Michigan (United States); C. D. Dowell, Jet Propulsion Lab. (United States); J. Glenn, Univ. of Colorado at Boulder (United States); S. Golwala, California Institute of Technology (United States); C. McKenney, Jet Propulsion Lab. (United States); J. J. McMahon, C. D. Munson, Univ. of Michigan (United States); M. Niemack, S. Parshley, G. Stacey, Cornell Univ. (United States)

915330 Vector near-field beam scanner for the SMA [9153-112]

R. D. Christensen, Smithsonian Astrophysical Observatory (United States); R. Rao, Institute of Astronomy and Astrophysics, Academia Sinica (Taiwan); T. K. Sridharan, E. Tong, HarvardSmithsonian Ctr. for Astrophysics (United States)

915332 The QUIJOTE TGI [9153-114]

R. Hoyland, M. Aguiar-González, R. Génova-Santosa, F. Gómez-Reñasco,

C. López-Caraballo, R. Rebolo-López, J. A. Rubiño-Martín, V. Sánchez-de la Rosa,

A. Vega-Moreno, T. Viera-Curbelo, A. Peláez-Santos, R. Vignaga, D. Tramonte, F. Poidevin, M. R. Pérez-de-Taoro, Instituto de Astrofísica de Canarias (Spain); E. Martínez-Gonzalez, CSIC-Univ. de Cantabria (Spain); B. Aja, E. Artal, J. Cagigas, J. L. Cano-de-Diego, E. M. Cuerno, L. de-la-Fuente, A. Pérez, D. Ortiz, J. V. Terán, E. Villa, Labs. de I+D de Telecomunicaciones (Spain); L. Piccirillo, The Univ. of Manchester (United Kingdom); M. Hobson, Cavendish Lab., Univ. of Cambridge (United Kingdom)

915334 The readout system for the ArTeMis camera [9153-119]

E. Doumayrou, M. Lortholary, L. Dumaye, G. Hamon, AIM Lab., CNRS, Paris Saclay (France) and IRFU-CEA (France)

915335 Development and characterization of the readout system for POLARBEAR-2 [9153-120] D. Barron, Univ. of California, San Diego (United States); P. A. R. Ade, Cardiff Univ. (United Kingdom); Y. Akiba, The Graduate Univ. for Advanced Studies (Japan); C. Aleman, 
K. Arnold, M. Atlas, Univ. of California, San Diego (United States); A. Bender, McGill Univ. (Canada); J. Borrill, Lawrence Berkeley National Lab. (United States) and Univ. of California, Berkeley (United States); S. Chapman, Dalhousie Univ. (Canada); Y. Chinone, High Energy Accelerator Research Organization, KEK (Japan) and Univ. of California, Berkeley (United States); A. Cukierman, Univ. of California, Berkeley (United States); M. Dobbs, McGill Univ. (Canada); T. Elleflot, Univ. of California, San Diego (United States); J. Errard, Univ. of California, Berkeley (United States) and Lawrence Berkeley National Lab. (United States); G. Fabbian, AstroParticle et Cosmologie, CNRS, Univ. Paris Diderot (France) and Observatoire de Paris, IRFU-CEA (France) and International School for Advanced Studies (Italy); G. Feng, Univ. of California, San Diego (United States); A. Gilbert, McGill Univ. (Canada); N. W. Halverson, Univ. of Colorado at Boulder (United States; M. Hasegawa, High Energy Accelerator Research Organization, KEK (Japan) and The Graduate Univ. for Advanced Studies (Japan); K. Hattori, High Energy Accelerator Research Organization, KEK (Japan); M. Hazumi, High Energy Accelerator Research Organization, KEK (Japan), The Graduate Univ. for Advanced Studies (Japan), and Kavli Institute for the Physics and Mathematics of the Universe, The Univ. of Tokyo (Japan); W. L. Holzapfel, Univ. of California, Berkeley (United States); Y. Hori, High Energy Accelerator Research Organization, KEK (Japan); Y. Inove, The Graduate Univ. for Advanced Studies (Japan); G. C. Jaehnig, Univ. of Colorado at Boulder (United States); N. Katayama, Kavli Institute for the Physics and Mathematics, The Univ. of Tokyo (Japan); B. Keating, Univ. of California, San Diego (United States); Z. Kermish, Princeton Univ. (United States); R. Keskitalo, Lawrence Berkeley National Lab. (United States); T. Kisner, Lawrence Berkeley National Lab. (United States) and Univ. of California, Berkeley (United States); M. Le Jeune, AstroParticle et Cosmologie, CNRS, Univ. Paris Diderot (France) and Observatoire de Paris, IRFU-CEA (France); A. T. Lee, Univ. of California, Berkeley (United States) and Lawrence Berkeley National Lab. (United States); F. Matsuda, Univ. of California, San Diego (United States); T. Matsumura, Japan Aerospace Exploration Agency (Japan); H. Morii, High Energy Accelerator Research Organization, KEK (Japan); M. J. Myers, Univ. of California, Berkeley (United States); M. Navaroli, Univ. of California, San Diego (United States); H. Nishino, Kavli Institute for the Physics and Mathematics of the Universe, The Univ. of Tokyo (Japan); T. Okamura, High Energy Accelerator Research Organization, KEK (Japan); J. Peloton, Observatoire de Paris, CNRS, Univ. Paris Diderot (France); G. Rebeiz, Univ. of California, San Diego (United States); C. L. Reichardt, P. L. Richards, Univ. of California, Berkeley (United States); C. Ross, Dalhousie Univ. (Canada); M. Sholl, Lawrence Berkeley National Lab. (United States); P. Siritanasak, Univ. of California, San Diego (United States); G. Smecher, Three-Speed Logic, Inc. (Canada); N. Stebor, Univ. of California, San Diego (United States); B. Steinbach, Univ. of California, Berkeley (United States); R. Stompor, AstroParticle et Cosmologie, CNRS, Univ. Paris Diderot (France) and Observatoire de Paris, IRFU-CEA (France); A. Suzuki, Univ. of California, Berkeley (United States); J. Suzuki, High Energy Accelerator Research Organization, KEK (Japan); S. Takada, National Institute for Fusion Science (Japan); S. Takakura, Osaka Univ. (Japan) and High Energy Accelerator Research Organization KEK (Japan); T. Tomaru, High Energy Accelerator Research Organization, KEK (Japan); B. Wilson, Univ. of California, San Diego (United States); H. Yamaguchi, High Energy Accelerator Research Organization, KEK (Japan); O. Zahn, Lawrence Berkeley National Lab. (United States)

915336 Development of a cryogenic DC-low noise amplifier for SQuID-based readout electronics [9153-121]

C. Macculi, INAF - Instituto di Astrofisica e Planétologie Spaziale di Roma (Italy); G. Torrioli, Istituto di Fotonica e Nanotecnologie, CNR (Italy); A. Di Giorgio, L. Spinoglio, L. Piro, INAF IASF Roma (Italy) 
915338 An RFI monitoring system based on a hybrid configuration for radioastronomy [9153-123] A. Melis, F. Gaudiomonte, INAF - Osservatorio Astronomico di Cagliari (Italy); M. Barbaro, Univ. degli Studi di Cagliari (Italy); R. Concu, C. Migoni, A. Trois, G. Valente, INAF Osservatorio Astronomico di Cagliari (Italy)

9153 3A Thermal and optical characterization for POLARBEAR-2 optical system [9153-125] Y. Inove, The Graduate Univ. for Advanced Studies (Japan); N. Stebor, Univ. of California, San Diego (United States); P. A. R. Ade, Cardiff Univ. (United Kingdom); Y. Akiba, The Graduate Univ. for Advanced Studies (Japan); K. Arnold, Univ. of California, San Diego (United States); A. E. Anthony, Univ. of Colorado at Boulder (United States); M. Atlas, Univ. of California, San Diego (United States); D. Barron, Univ. of California, San Diego (United States); A. Bender, McGill Univ. (Canada); D. Boettger, Univ. of California, San Diego (United States); J. Borrill, Lawrence Berkeley National Lab. (United States) and Univ. of California, Berkeley (United States); S. Chapman, Dalhousie Univ. (Canada); Y. Chinone, High Energy Accelerator Research Organization, KEK (Japan) and Univ. of California, Berkeley (United States); A. Cukierman, Univ. of California, Berkeley (United States); M. Dobbs, McGill Univ. (Canada); T. Elleflot, Univ. of California, San Diego (United States); J. Errard, Univ. of California, Berkeley (United States) and Lawrence Berkeley National Lab. (United States); G. Fabbian, AstroParticle et Cosmologie, CNRS, Univ. Paris Diderot (France), Observatoire de Paris, IRFU-CEA (France), and Scuola Internazionale Superiore di Studi Avanzati (Italy); C. Feng, Univ. of California, San Diego (United States); A. Gilbert, McGill Univ. (Canada); N. W. Halverson, Univ. of Colorado at Boulder (United States); M. Hasegawa, High Energy Accelerator Research Organization, KEK (Japan) and The Graduate Univ. for Advanced Studies (Japan); K. Hattori, High Energy Accelerator Research Organization, KEK (Japan); M. Hazumi, High Energy Accelerator Research Organization, KEK (Japan), The Graduate Univ. of Advanced Studies (Japan), and Kavli Institute for the Physics and Mathematics of the Universe, The Univ. of Tokyo (Japan); W. L. Holzapfel, Univ. of California, Berkeley (United States); Y. Hori, High Energy Accelerator Research Organization, KEK (Japan); G. C. Jaehnig, Univ. of Colorado at Boulder (United States); A. H. Jaffe, Imperial College London (United Kingdom); N. Katayama, Kavli Institute for the Physics and Mathematics, The Univ. of Tokyo (Japan); B. Keating, Univ. of California, San Diego (United States); Z. Kermish, Princeton Univ. (United States); R. Keskitalo, Lawrence Berkeley National Lab. (United States); T. Kisner, Lawrence Berkeley National Lab. (United States) and Univ. of California, Berkeley (United States); M. Le Jeune, AstroParticle et Cosmologie, CNRS, Univ. Paris Diderot (France) and Observatoire de Paris, IRFU-CEA (France); A. T. Lee, Univ. of California, Berkeley (United States) and Lawrence Berkeley National Lab. (United States); E. M. Leitch, Univ. of Chicago (United States) and Kavli Institute for Cosmological Physics, The Univ. of Chicago (United States); E. Linder, Lawrence Berkeley National Lab. (United States); F. Matsuda, Univ. of California, San Diego (United States); T. Matsumura, Japan Aerospace Exploration Agency (Japan); X. Meng, Univ. of California, Berkeley (United States); H. Morii, High Energy Accelerator Research Organization, KEK (Japan); M. J. Myers, Univ. of California, Berkeley (United States); M. Navaroli, Univ. of California, San Diego (United States); H. Nishino, Kavli Institute for the Physics and Mathematics, The Univ. of Tokyo (Japan); T. Okamura, High Energy Accelerator Research Organization, KEK (Japan); H. Paar, Univ. of California, San Diego (United States); J. Peloton, D. Poletti, Observatoire de Paris, CNRS, UNiv. Paris Diderot (France) and IRFU-CEA (France); G. Rebeiz, Univ. of California, San Diego (United States); C. L. Reichardt, P. L. Richards, Univ. of California, Berkeley (United States); C. Ross, Dalhousie Univ. (Canada); D. E. Schenck, Univ. of Colorado at Boulder (United States); B. D. Sherwin, Univ. of California, Berkeley (United States); P. Siritanasak, Univ. of California, San Diego (United States); G. Smecher, Three-Speed Logic, Inc. (Canada); M. Sholl, Lawrence Berkeley National Lab. (United States); B. Steinbach, Univ. of California, Berkeley 
(United States); R. Stompor, Observatoire de Paris, CNRS, Univ. Paris Diderot (France) and IRFU-CEA (France); A. Suzuki, Univ. of California, Berkeley (United States); J. Suzuki, High Energy Accelerator Research Organization, KEK (Japan); S. Takada, National Institute for Fusion Science (Japan); S. Takakura, Osaka Univ. (Japan) and High Energy Accelerator Research Organization, KEK (Japan); T. Tomaru, High Energy Accelerator Research Organization, KEK (Japan); B. Wilson, A. Yadav, Univ. of California, San Diego (United States); H. Yamaguchi, High Energy Accelerator Research Organization, KEK (Japan); O. Zahn, Lawrence Berkeley National Lab. (United States)

9153 3B Keck array and BICEP3: spectral characterization of 5000+ detectors [9153-126] K. S. Karkare, Harvard-Smithsonian Ctr. for Astrophysics (United States); P. A. R. Ade, Cardiff Univ. (United Kingdom); Z. Ahmed, Stanford Univ. (United Kingdom) and Kavli Institute for Particle Astrophysics and Cosmology, SLAC National Accelerator Lab. (United States); R. W. Aikin, California Institute of Technology (United States); K. D. Alexander, HarvardSmithsonian Ctr. for Astrophysics (United States); M. Amiri, The Univ. of British Columbia (Canada); D. Barkats, Joint ALMA Observatory (Chile); S. J. Benton, Univ. of Toronto (Canada); C. A. Bischoff, Harvard-Smithsonian Ctr. for Astrophysics (United States); J. J. Bock, California Institute of Technology (United States) and Jet Propulsion Lab. (United States); J. A. Bonetti, Jet Propulsion Lab. (United States); J. A. Brevik, California Institute of Technology (United States); I. Buder, Harvard-Smithsonian Ctr. for Astrophysics (United States); E. W. Bullock, Univ. of Minnesota (United States); B. Burger, The Univ. of British Columbia (Canada); J. Connors, Harvard-Smithsonian Ctr. for Astrophysics (United States); B. P. Crill, California Institute of Technology (United States) and Jet Propulsion Lab. (United States); G. Davis, The Univ. of British Columbia (Canada); C. D. Dowell, Jet Propulsion Lab. (United States); L. Duband, Commissariat à l'Énergie Atomique (France); J. P. Filippini, California Institute of Technology (United States); S. T. Fliescher, Univ. of Minnesota (United States); S. R. Golwala, California Institute of Technology (United States); M. S. Gordon, Harvard-Smithsonian Ctr. for Astrophysics (United States); J. A. Grayson, Stanford Univ. (United States); M. Halpern, M. Hasselfield, The Univ. of British Columbia (Canada); S. R. Hildebrandt, California Institute of Technology (United States) and Jet Propulsion Lab. (United States); G. C. Hilton, National Institute of Standards and Technology (United States); V. V. Hristov, H. Hui, California Institute of Technology (United States); K. D. Irwin, Stanford Univ. (United States), Kavli Institute for Particle Astrophysics and Cosmology, SLAC National Accelerator Lab. (United States), and National Institute of Standards and Technology (United States); J. H. Kang, E. Karpel, Stanford Univ. (United States); S. Kefeli, California Institute of Technology (United States); S. A. Kernasovskiy, Stanford Univ. (United States); J. M. Kovac, Harvard-Smithsonian Ctr. for Astrophysics (United States); C. L. Kuo, Stanford Univ. (United States) and Kavli Institute for Particle Astrophysics and Cosmology, SLAC National Accelerator Lab. (United States); E. M. Leitch, Univ. of Chicago (United States); M. Lueker, P. Mason, California Institute of Technology (United States); K. G. Megerian, Jet Propulsion Lab. (United States); C. B. Netterfield, Univ. of Toronto (Canada) and Canadian Institute for Advanced Research (Canada); H. T. Nguyen, R. O'Brient, Jet Propulsion Lab. (United States); R. W. Ogburn IV, Stanford Univ. (United States) and Kavli Institute for Particle Astrophysics and Cosmology, SLAC National Accelerator Lab. (United States); C. L. Pryke, Univ. of Minnesota (United States); C. D. Reintsema, National Institute of Standards and Technology (United States); S. Richter, Harvard-Smithsonian Ctr. for Astrophysics (United States); R. Schwarz, Univ. of Minnesota (United States); C. D. Sheehy, Univ. of Minnesota (United States) and The Univ. of Chicago (United States); Z. K. Staniszewski, California Institute of Technology (United States) and Jet Propulsion Lab. (United States); R. V. Sudiwala, Cardiff Univ. (United Kingdom); G. P. Teply, California Institute of Technology (United States); K. L. Thompson, Stanford Univ. (United States) and Kavli Institute for Particle Astrophysics and Cosmology, SLAC National Accelerator Lab. (United States); 
J. E. Tolan, Stanford Univ. (United States); A. D. Turner, Jet Propulsion Lab. (United States); A. Vieregg, Harvard-Smithsonian Ctr. for Astrophysics (United States) and The Univ. of Chicago (United States); A. Weber, Jet Propulsion Lab. (United States) and California Institute of Technology (United States); C. L. Wong, Harvard-Smithsonian Ctr. for Astrophysics (United States); W. L. K. Wu, Stanford Univ. (United States); K. W. Yoon, Stanford Univ. (United States) and Kavli Institute for Particle Astrophysics and Cosmology, SLAC National Accelerator Lab. (United States)

9153 3C Kilopixel backshort-under-grid arrays for the Primordial Inflation Polarization Explorer [9153-127]

C. A. Jhabvala, D. J. Benford, NASA Goddard Space Flight Ctr. (United States); R. P. Brekosky, M.-P. Chang, N. P. Costen, A. M. Datesman, NASA Goddard Space Flight Ctr. (United States) and Stinger Ghaffarian Technologies, Inc. (United States); G. C. Hilton, National Institute of Standards and Technology (United States); K. D. Irwin, Stanford Univ. (United States); A. J. Kogut, NASA Goddard Space Flight Ctr. (United States); J. Lazear, NASA Goddard Space Flight Ctr. (United States) and Johns Hopkins Univ. (United States); E. S. Leong, NASA Goddard Space Flight Ctr. (United States) and Stinger Ghaffarian Technologies, Inc. (United States); S. F. Maher, NASA Goddard Space Flight Ctr. (United States) and Science Systems and Applications, Inc. (United States); T. M. Miller,

S. H. Moseley, NASA Goddard Space Flight Ctr. (United States); E. H. Sharp, NASA Goddard Space Flight Ctr. (United States), Global Science \& Technology, Inc. (United States), and Johns Hopkins Univ. (United States); J. G. Staguhn, NASA Goddard Space Flight Ctr. (United States) and Johns Hopkins Univ. (United States); E. J. Wollack, NASA Goddard Space Flight Ctr. (United States)

$91533 \mathrm{~F} \quad$ Methodology for a sub-millimeter near-field beam pattern measurement system [9153-131] K. K. Davis, C. Groppi, H. Mani, C. Wheeler, Arizona State Univ. (United States); C. Walker, The Univ. of Arizona (United States)

Author Index 
Proc. of SPIE Vol. $9153915301-28$

Downloaded From: https://www.spiedigitallibrary.org/conference-proceedings-of-spie on 26 Apr 2023 Terms of Use: https://www.spiedigitallibrary.org/terms-of-use 


\section{Conference Committee}

Symposium Chairs

Gillian S. Wright, UK Astronomy Technology Centre (United Kingdom)

Luc Simard, National Research Council Canada (Canada)

Symposium Co-chairs

Colin Cunningham, UK Astronomy Technology Centre (United Kingdom)

Masanori lye, National Astronomical Observatory of Japan (Japan)

Conference Chairs

Wayne S. Holland, UK Astronomy Technology Centre (United Kingdom)

Jonas Zmuidzinas, California Institute of Technology (United States)

Conference Program Committee

Jian-Rong Gao, SRON Netherlands Institute for Space Research

(Netherlands) and Delft University of Technology (Netherlands)

Kent D. Irwin, Stanford University (United States)

J. Anthony Murphy, National University of Ireland, Maynooth (Ireland)

Albrecht Poglitsch, Max-Planck-Institut für extraterrestrische Physik

(Germany)

Karl Schuster, IRAM-Domaine University de Grenoble (France)

Gordon J. Stacey, Cornell University (United States)

Christopher K. Walker, The University of Arizona (United States)

Session Chairs

1 Current/Near-Term Cameras and Arrays

Jonas Zmuidzinas, California Institute of Technology (United States)

2 Transition-Edge Sensors: Theory and Design

Kent D. Irwin, Stanford University (United States)

3 Transition-Edge Sensors: Performance and Developments

Jian-Rong Gao, SRON Netherlands Institute for Space Research

(Netherlands) and Delft University of Technology (Netherlands)

4 Future Cameras and Arrays

Christopher Groppi, Arizona State University (United States) 
5 Coherent Detector Technology

Johannes G. Staguhn, NASA Goddard Space Flight Center (United States)

$6 \quad$ Kinetic Inductance Detectors

Jonas Zmuidzinas, California Institute of Technology (United States)

7 CMB Instruments: Current and Near-Term

Michael D. Niemack, Cornell University (United States)

8 Optics and Components

J. Anthony Murphy, National University of Ireland, Maynooth (Ireland)

9 Multiplexing and Readout Systems

Jian-Rong Gao, SRON Netherlands Institute for Space Research (Netherlands) and Delft University of Technology (Netherlands)

10 CMB Instruments: New Developments I

Adrian Lee, University of California, Berkeley (United States)

11 CMB Instruments: New Developments II

Gordon J. Stacey, Cornell University (United States)

12 Terahertz Technology

Christopher Groppi, Arizona State University (United States)

13 Emerging Concepts and New Instruments

Jonas Zmuidzinas, California Institute of Technology (United States) 